\title{
Evaluation of Thermal anomaly Preceding Northern Red Sea Earthquake, the 16th June 2020
}

\author{
Emad K. Mohamed ${ }^{1}\left[\right.$ [Dedhat Elrayess ${ }^{1} \cdot$ Khaled Omar $^{1}$
}

Received: 5 September 2021 / Accepted: 15 December 2021 / Published online: 24 January 2022

(c) The Author(s) 2022

\begin{abstract}
On the 16th June, 2020, a moderate earthquake $(\mathrm{Mw}=5.2)$ hit the Northern Red Sea region, Egypt, that was felt throughout the Hurghada and Sharm El-Sheikh cities and the surrounding areas without any damages. The thermal anomaly before the earthquakes was widely studied with satellite data, such as NOAA/AVHRR and MODIS. The case study aims to monitor and demonstrate the possibility of any variation of the thermal anomaly of sea surface temperature (SST) before and after the 16th June 2020 earthquake and to correlate the results with the previous heat flow study (deep thermal action). The Daytime/Nighttime (SST) data are retrieved from the OBPG serves as a Distributed Active Archive Center (OB. DAAC). The outputs indicated a thermal anomaly on the June 12th, 2020 a few days before the earthquake, covered a large area around the epicenter $60 \mathrm{~km}$ impact area, and reached a high value on the 15th June 2020, one day before the earthquake. For the deep thermal action of the entire crust, the earthquake frequency distributions presumed from the reviewed catalogue indicated that the peak of the seismicity is concentrated close to the center of the rift axis in the Northern Red Sea. The heat flow measurements are increased toward the center of the Red Sea rift and decreased toward both sides, generating some partial melt of the rocks and producing crustal subsidence at the center of the Red Sea rift. These results are compatible with the pattern of the seismic activity and heat flow effect around the epicenter. It could be considered as a short-term precursor of the earthquake.
\end{abstract}

Keywords Thermal anomaly $\cdot$ Sea surface temperature (SST) Heat flow $\cdot$ The seismic activity $\cdot$ Earth Observing System

\section{Introduction}

The establishment of earthquake forecasting systems would be helpful to mitigate the effects of earthquakes, especially for countries along tectonic plate boundaries [1]. Satellite remote sensing techniques can provide an effective method for monitoring the pre-seismic processes along active fault zones. Many statistical studies have used large earthquakes to identify a significant correlation between the pre-seismic signals and upcoming earthquakes with various analytical methods.

The earthquake precursors are the abnormal changes in the physical parameters or processes occurring before the large earthquakes. In the last three decades, many researchers have

Emad K. Mohamed

ekamal@ nriag.sci.eg

1 Department of Seismology, National Research Institute of Astronomy and Geophysics - NRIAG, 11421 Helwan, Cairo, Egypt studied the thermal anomalies were observed before the large earthquakes using satellite data [2-15]. In the history of thermal anomaly research, it is undeniable that there are abnormal radiation anomalies before the large and major earthquakes, as suggested by many authors [5, 16] [17-22], as well as moderate earthquakes [18], and [19] they have studied the earthquakes with $\mathrm{Mw}>4$. Therefore, the thermal anomaly has been interpreted as a pre-seismic precursor in earthquake prediction and forecasting.

The available information and knowledge of the earthquakes should be considered during the planning and implementation of any projects to save investments and achieve sustainable development. Therefore, it is imperative to study the non-seismic phenomena such as the magnetic field variation, ground radon emission, land surface temperature (LST), sea surface temperature (SST), and outgoing longwave radiation (OLR) variations that can precede the seismic activity. Moreover, heat flow anomalies also resulted from plate tectonic processes associated with arc volcanism, hot spot traces, back-arc basins, and continental rifting. 
Fig. 1 The location map of the study area shows the seismicity from 1997-2020 and heat flow distributions [26], as denoted by purple, blue, and green lines (points)

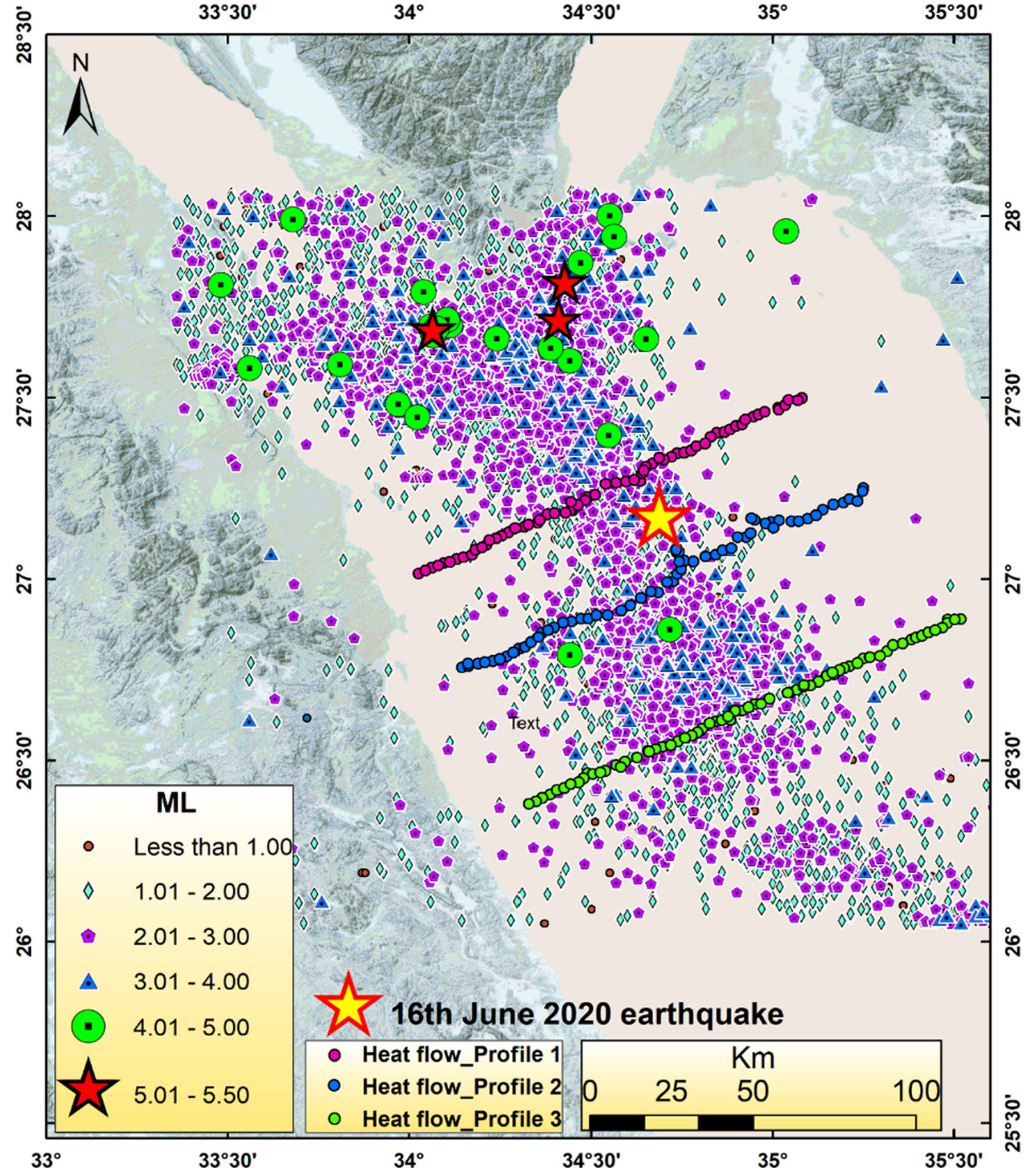

Most of Egypt's seismic active zones occur in the northern part of the country, including the Northern Red Sea, Gulf of Aqaba, Gulf of Suez, Cairo-Suez district, Southwest of Greater Cairo (Dahshour area), and in the Eastern Mediterranean region, as well as, the low seismic activities on the central and southern parts of Egypt [23]. The earthquakes range from small to moderate magnitudes. The significant historical earthquakes that occurred are Shadwan earthquake $(\mathrm{Mb}=6,1969)$ and Aqaba earthquake, $(\mathrm{Mb}=$ 7, 1995). However, instrumental earthquakes are (Beni Suef earthquake, 2006, $\mathrm{M}_{\mathrm{L}}=5.2$ ), (Asuit earthquake, 2003, $\mathrm{M}_{\mathrm{L}}$ $=5.1$ ), and (Suez earthquake, $2014, \mathrm{M}_{\mathrm{L}}=4.3$ ) while more recently occurred on the 16 th June 2020 , with $\mathrm{M}_{\mathrm{W}}=5.2$. This earthquake was felt throughout the Hurghada and different areas surrounding the epicenter, with no reported damage.

The Northern Red Sea was a continental rift in the process of transition from continental to oceanic spreading. It is underlain by the stretching and thinning of the continental crust, as suggested by Cochran [24, 25] and [26]. It is affected by the structural elements and tectonics of the Southeast of the Mediterranean Sea and the Northeastern corner of the African plate [27-33] and by the tectonic of the Sinai subplate and the Gulf of Suez-Red Sea Rift System [34-36]. In general, the Gulf of Suez and the Red Sea depressions were formed by the anticlockwise rotation of the Arabian plate away from the Africa plate [24].

Heat flow is generated from plate tectonic processes, whereas increasing the temperature with depth inside deep mines or earth interiors leads to heat flow anomalies. Moreover, heat flow is associated with arc volcanism, hot lavas, back-arc basins, and continental rifting. The authors have done previous heat flow studies along the Suez and the Red Sea rifts [37-43]. Figure 1 shows the location map of the study area with the seismicity and heat flow locations. 
Table 1 Heat Flow Measurements at Profile 1 (Northern Line)

\begin{tabular}{|c|c|c|c|c|c|c|c|}
\hline No. of the Site & Latitude & Longitude & Elevation & Gradient & Heat_Flow & Conductivity & Reference \\
\hline 1 & 27.0145 & 34.0263 & -429 & 94 & 108 & 1.15 & Martinez and Cochran1989 \\
\hline 2 & 27.0233 & 34.0455 & -447 & 89 & 101 & 1.14 & Martinez and Cochran1989 \\
\hline 3 & 27.0315 & 34.0622 & -609 & 108 & 122 & 1.14 & Martinez and Cochran1989 \\
\hline 4 & 27.0365 & 34.0805 & -546 & 91 & 103 & 1.13 & Martinez and Cochran 1989 \\
\hline 5 & 27.0435 & 34.0963 & -660 & 100 & 112 & 1.13 & Martinez and Cochran1989 \\
\hline 6 & 27.0468 & 34.1115 & -737 & 71 & 80 & 1.13 & Martinez and Cochran1989 \\
\hline 7 & 27.0545 & 34.131 & -972 & 155 & 172 & 1.13 & Martinez and Cochran1989 \\
\hline 8 & 27.059 & 34.1507 & -970 & 153 & 170 & 1.12 & Martinez and Cochran1989 \\
\hline 9 & 27.0657 & 34.173 & -765 & 142 & 156 & 1.12 & Martinez and Cochran1989 \\
\hline 10 & 27.0807 & 34.1835 & -770 & 136 & 150 & 1.11 & Martinez and Cochran1989 \\
\hline 11 & 27.086 & 34.2008 & -746 & 112 & 122 & 1.11 & Martinez and Cochran1989 \\
\hline 12 & 27.0932 & 34.2133 & -750 & 126 & 137 & 1.11 & Martinez and Cochran1989 \\
\hline 13 & 27.1063 & 34.2218 & -803 & 103 & 111 & 1.11 & Martinez and Cochran1989 \\
\hline 14 & 27.1112 & 34.2393 & -845 & 125 & 134 & 1.1 & Martinez and Cochran1989 \\
\hline 15 & 27.1185 & 34.254 & -840 & 127 & 135 & 1.1 & Martinez and Cochran1989 \\
\hline 16 & 27.1282 & 34.2748 & -855 & 157 & 166 & 1.1 & Martinez and Cochran1989 \\
\hline 17 & 27.1385 & 34.2902 & -860 & 172 & 182 & 1.09 & Martinez and Cochran1989 \\
\hline 18 & 27.1392 & 34.292 & -860 & 154 & 163 & 1.09 & Martinez and Cochran1989 \\
\hline 19 & 27.1425 & 34.3137 & -925 & 214 & 225 & 1.09 & Martinez and Cochran1989 \\
\hline 20 & 27.1493 & 34.327 & -948 & 186 & 195 & 1.08 & Martinez and Cochran1989 \\
\hline 21 & 27.1557 & 34.3512 & -1128 & 188 & 196 & 1.08 & Martinez and Cochran1989 \\
\hline 22 & 27.1623 & 34.3575 & -1155 & 180 & 187 & 1.08 & Martinez and Cochran1989 \\
\hline 23 & 27.1782 & 34.3787 & -1187 & 242 & 249 & 1.08 & Martinez and Cochran1989 \\
\hline 24 & 27.1808 & 34.399 & -1107 & 225 & 232 & 1.08 & Martinez and Cochran1989 \\
\hline 25 & 27.1827 & 34.4278 & -1134 & 265 & 270 & 1.08 & Martinez and Cochran1989 \\
\hline 26 & 27.1878 & 34.4488 & -1400 & 420 & 428 & 1.07 & Martinez and Cochran1989 \\
\hline 27 & 27.188 & 34.4418 & -1275 & 340 & 347 & 1.07 & Martinez and Cochran1989 \\
\hline 28 & 27.2038 & 34.4618 & -1365 & 172 & 175 & 1.07 & Martinez and Cochran1989 \\
\hline 29 & 27.212 & 34.4443 & -1194 & 0 & 0 & 1.07 & Martinez and Cochran1989 \\
\hline 30 & 27.2158 & 34.4825 & -1237 & 328 & 335 & 1.06 & Martinez and Cochran1989 \\
\hline 31 & 27.2248 & 34.4907 & -1090 & 662 & 369 & 1.06 & Martinez and Cochran1989 \\
\hline 32 & 27.2323 & 34.5108 & -1075 & 361 & 368 & 1.06 & Martinez and Cochran1989 \\
\hline 33 & 27.2615 & 34.5388 & -1069 & 290 & 296 & 1.06 & Martinez and Cochran1989 \\
\hline 34 & 27.2645 & 34.5687 & -1107 & 294 & 297 & 1.06 & Martinez and Cochran1989 \\
\hline 35 & 27.2687 & 34.5957 & -1135 & 308 & 311 & 1.06 & Martinez and Cochran1989 \\
\hline 36 & 27.2708 & 34.634 & -1205 & 207 & 209 & 1.06 & Martinez and Cochran1989 \\
\hline 37 & 27.2725 & 34.6175 & -1200 & 177 & 179 & 1.05 & Martinez and Cochran1989 \\
\hline 38 & 27.2907 & 34.6393 & -1135 & 171 & 173 & 1.05 & Martinez and Cochran1989 \\
\hline 39 & 27.2987 & 34.6443 & -1147 & 0 & 0 & 1.05 & Martinez and Cochran1989 \\
\hline 40 & 27.3087 & 34.6492 & -1030 & 162 & 164 & 1.05 & Martinez and Cochran1989 \\
\hline 41 & 27.3183 & 34.669 & -977 & 205 & 209 & 1.05 & Martinez and Cochran1989 \\
\hline 42 & 27.3288 & 34.6987 & -1020 & 180 & 184 & 1.05 & Martinez and Cochran1989 \\
\hline 43 & 27.3333 & 34.6868 & -1023 & 164 & 167 & 1.05 & Martinez and Cochran1989 \\
\hline 44 & 27.3358 & 34.7207 & -995 & 257 & 262 & 1.05 & Martinez and Cochran1989 \\
\hline 45 & 27.3462 & 34.7358 & -985 & 290 & 296 & 1.04 & Martinez and Cochran1989 \\
\hline
\end{tabular}


Table 1 continued

\begin{tabular}{|c|c|c|c|c|c|c|c|}
\hline No. of the Site & Latitude & Longitude & Elevation & Gradient & Heat_Flow & Conductivity & Reference \\
\hline 46 & 27.3487 & 34.7552 & -980 & 262 & 270 & 1.04 & Martinez and Cochran1989 \\
\hline 47 & 27.3543 & 34.7752 & -903 & 241 & 248 & 1.04 & Martinez and Cochran1989 \\
\hline 48 & 27.3657 & 34.7898 & -833 & 228 & 235 & 1.04 & Martinez and Cochran1989 \\
\hline 49 & 27.3728 & 34.8128 & -803 & 169 & 174 & 1.04 & Martinez and Cochran1989 \\
\hline 50 & 27.391 & 34.8295 & -835 & 193 & 201 & 1.04 & Martinez and Cochran1989 \\
\hline 51 & 27.4027 & 34.846 & -857 & 293 & 305 & 1.04 & Martinez and Cochran1989 \\
\hline 52 & 27.4052 & 34.8658 & -831 & 208 & 216 & 1.04 & Martinez and Cochran1989 \\
\hline 53 & 27.4118 & 34.8823 & -847 & 187 & 194 & 1.04 & Martinez and Cochran1989 \\
\hline 54 & 27.4213 & 34.8992 & -820 & 174 & 183 & 1.04 & Martinez and Cochran1989 \\
\hline 55 & 27.4262 & 34.9155 & -807 & 169 & 177 & 1.03 & Martinez and Cochran1989 \\
\hline 56 & 27.439 & 34.9238 & -815 & 157 & 165 & 1.03 & Martinez and Cochran1989 \\
\hline 57 & 27.4472 & 34.9458 & -835 & 171 & 180 & 1.03 & Martinez and Cochran1989 \\
\hline 58 & 27.4533 & 34.961 & -830 & 161 & 171 & 1.03 & Martinez and Cochran1989 \\
\hline 59 & 27.4607 & 34.9782 & -806 & 121 & 128 & 1.03 & Martinez and Cochran1989 \\
\hline 60 & 27.466 & 35.016 & -765 & 167 & 179 & 1.03 & Martinez and Cochran1989 \\
\hline 61 & 27.4713 & 35.0148 & -765 & 184 & 197 & 1.03 & Martinez and Cochran1989 \\
\hline 62 & 27.4792 & 35.0348 & -725 & 139 & 149 & 1.03 & Martinez and Cochran1989 \\
\hline 63 & 27.492 & 35.0692 & -693 & 119 & 129 & 1.02 & Martinez and Cochran1989 \\
\hline 64 & 27.4927 & 35.0438 & -717 & 127 & 137 & 1.02 & Martinez and Cochran1989 \\
\hline 65 & 27.4988 & 35.0807 & -690 & 127 & 137 & 1.02 & Martinez and Cochran1989 \\
\hline
\end{tabular}

The local sources of heat flow include frictional heating along earthquake faults. This friction can be sufficiently intense to melt the rock, producing pseudotachylite partially. Indeed, a small amount of heat trapped by geothermal power plants located along major active faults, such as the San Andreas fault in California or active faults in Nevada, probably comes from frictional heating as rocks grind past on either side of the fault.

Figure 1 shows a conceptual diagram of the possible mechanism of stresses developed at ocean ridges due to collision of plate boundaries, venting additional hot fluid, water vapor, and other gases (from the earth's asthenosphere/lower mantle). Change in ocean thermal gradients during the seismic cycle of enhanced tectonic activity results in more heat flow than normal, and subsequent warming of the sea surface.

In this study, we have used MODIS SST data to monitor the variation of sea surface temperature before and after the 16th June 2020 Northern Red Sea earthquake to identify the thermal anomalies based on a statistical analysis of running median and inter quartile range (IQR). This method signifies the abnormality in a daily time series for 15 days before and five days after the earthquake, which can be associated with seismic activity.

This study is very important and significant because the area of interest provides a considerable resource for fishing, coral reefs, oil and gas extraction, and tourism. Moreover, the Red Sea links the European harbors to China and Eastern
Asia, supporting a high volume of shipping activity. The risk and vulnerability of the Red Sea to SST thermal trends are highly expected during the current century [44], which may lead to harmful impacts on marine entities.

\section{Sea Surface Temperatures (SST)}

The SST is one of the most important variables used to understand the ocean and atmospheric phenomena, such as climate change, air-sea interaction, and earthquake forecasting. SST data provided by the OBPG serve as a Distributed Active Archive Center (OB.DAAC), responsible for archiving the satellite ocean biologic data produced or collected under NASA's Earth Observing System Data and Information System (EOSDIS).

MODIS (SST) data have high confidence, as they significantly correlate to the in situ surface temperature measurements [45, 46]. Chakravarty had studied SST Variability Derived from AQUA/AMSR-E Satellite data near the Sumatra region affected by undersea earthquakes [47]. This product returns the skin temperature of the ocean by ${ }^{\circ} \mathrm{C}$. The long-wave infrared (LWIR) SST products use the 11 and $12 \mu \mathrm{m}$ spectral bands, measured by MODIS and VIIRS infrared radiometers. The validation of satellite skin SST for a climate data record and the use of shipboard radiometers can be found in $[48,49]$. 
Table 2 Heat Flow Measurements at Profile 2 (Middle Line)

\begin{tabular}{|c|c|c|c|c|c|c|c|}
\hline No. of the Site & Latitude & Longitude & Elevation & Gradient & Heat_Flow & Conductivity & Reference \\
\hline 1 & 27.0738 & 34.735 & -1441 & 699 & 615 & 0.88 & Martinez and Cochran 1989 \\
\hline 2 & 27.0742 & 34.7388 & -1441 & 375 & 330 & 0.88 & Martinez and Cochran1989 \\
\hline 3 & 26.9942 & 34.7265 & -1236 & 360 & 320 & 0.89 & Martinez and Cochran1989 \\
\hline 4 & 27.0128 & 34.736 & -1220 & 350 & 312 & 0.89 & Martinez and Cochran1989 \\
\hline 5 & 27.0277 & 34.7475 & -1220 & 351 & 309 & 0.88 & Martinez and Cochran1989 \\
\hline 6 & 27.1563 & 34.9953 & -920 & 280 & 266 & 0.95 & Martinez and Cochran1989 \\
\hline 7 & 27.1623 & 34.9498 & -865 & 281 & 264 & 0.94 & Martinez and Cochran1989 \\
\hline 8 & 27.0612 & 34.8138 & -1115 & 288 & 256 & 0.89 & Martinez and Cochran1989 \\
\hline 9 & 26.99 & 34.7082 & -1278 & 283 & 252 & 0.89 & Martinez and Cochran1989 \\
\hline 10 & 27.0508 & 34.756 & -1260 & 281 & 247 & 0.88 & Martinez and Cochran1989 \\
\hline 11 & 27.1527 & 34.9805 & -835 & 251 & 236 & 0.94 & Martinez and Cochran1989 \\
\hline 12 & 26.8818 & 34.4453 & -865 & 239 & 229 & 0.96 & Martinez and Cochran1989 \\
\hline 13 & 27.1152 & 34.926 & -865 & 247 & 227 & 0.92 & Martinez and Cochran1989 \\
\hline 14 & 27.1257 & 34.939 & -875 & 243 & 224 & 0.92 & Martinez and Cochran1989 \\
\hline 15 & 27.0667 & 34.8427 & -1170 & 245 & 221 & 0.9 & Martinez and Cochran1989 \\
\hline 16 & 27.0478 & 34.7817 & -1150 & 247 & 220 & 0.89 & Martinez and Cochran1989 \\
\hline 17 & 26.8905 & 34.4707 & -845 & 228 & 217 & 0.95 & Martinez and Cochran1989 \\
\hline 18 & 26.8072 & 34.303 & -717 & 211 & 217 & 1.03 & Martinez and Cochran1989 \\
\hline 19 & 27.1665 & 34.9405 & -910 & 226 & 210 & 0.93 & Martinez and Cochran1989 \\
\hline 20 & 26.8902 & 34.4918 & -832 & 221 & 208 & 0.94 & Martinez and Cochran1989 \\
\hline 21 & 27.1143 & 34.9038 & -840 & 224 & 204 & 0.91 & Martinez and Cochran1989 \\
\hline 22 & 27.1592 & 35.0508 & -920 & 201 & 193 & 0.96 & Martinez and Cochran1989 \\
\hline 23 & 26.8797 & 34.4217 & -924 & 200 & 192 & 0.96 & Martinez and Cochran1989 \\
\hline 24 & 27.0785 & 34.8612 & -930 & 212 & 191 & 0.9 & Martinez and Cochran1989 \\
\hline 25 & 26.9477 & 34.6362 & -935 & 209 & 190 & 0.91 & Martinez and Cochran1989 \\
\hline 26 & 27.0738 & 34.742 & -1330 & 215 & 189 & 0.88 & Martinez and Cochran1989 \\
\hline 27 & 27.1608 & 35.018 & -960 & 193 & 183 & 0.95 & Martinez and Cochran1989 \\
\hline 28 & 27.0845 & 34.8857 & -890 & 202 & 181 & 0.9 & Martinez and Cochran1989 \\
\hline 29 & 26.7738 & 34.231 & -679 & 168 & 181 & 1.08 & Martinez and Cochran1989 \\
\hline 30 & 26.9005 & 34.5145 & -920 & 190 & 179 & 0.94 & Martinez and Cochran1989 \\
\hline 31 & 27.2047 & 35.166 & -730 & 178 & 178 & 1 & Martinez and Cochran1989 \\
\hline 32 & 27.1658 & 35.096 & -874 & 180 & 175 & 0.97 & Martinez and Cochran1989 \\
\hline 33 & 26.9273 & 34.6078 & -938 & 182 & 167 & 0.92 & Martinez and Cochran1989 \\
\hline 34 & 27.1583 & 35.0717 & -925 & 172 & 167 & 0.97 & Martinez and Cochran1989 \\
\hline 35 & 27.1898 & 35.1385 & -790 & 163 & 161 & 0.99 & Martinez and Cochran1989 \\
\hline 36 & 26.8122 & 34.3178 & -735 & 158 & 161 & 1.02 & Martinez and Cochran1989 \\
\hline 37 & 26.9007 & 34.5448 & -884 & 172 & 160 & 0.93 & Martinez and Cochran1989 \\
\hline 38 & 26.8665 & 34.3973 & -694 & 164 & 159 & 0.97 & Martinez and Cochran1989 \\
\hline 39 & 27.2095 & 35.1942 & -700 & 148 & 149 & 1.01 & Martinez and Cochran 1989 \\
\hline 40 & 27.1757 & 35.119 & -899 & 149 & 146 & 0.98 & Martinez and Cochran1989 \\
\hline 41 & 27.2408 & 35.2475 & -681 & 138 & 144 & 1.04 & Martinez and Cochran1989 \\
\hline 42 & 26.7857 & 34.2705 & -825 & 125 & 131 & 1.05 & Martinez and Cochran1989 \\
\hline 43 & 26.8517 & 34.3628 & -695 & 125 & 124 & 0.99 & Martinez and Cochran1989 \\
\hline 44 & 26.8255 & 34.3332 & -743 & 123 & 124 & 1.01 & Martinez and Cochran1989 \\
\hline 45 & 26.8582 & 34.3805 & -695 & 124 & 122 & 0.98 & Martinez and Cochran1989 \\
\hline 46 & 26.8392 & 34.3532 & -743 & 121 & 121 & 1 & Martinez and Cochran1989 \\
\hline
\end{tabular}


Table 2 continued

\begin{tabular}{llllllll}
\hline No. of the Site & Latitude & Longitude & Elevation & Gradient & Heat_Flow & Conductivity & Reference \\
\hline 47 & 27.2198 & 35.2122 & -690 & 119 & 121 & 1.02 & Martinez and Cochran1989 \\
48 & 26.7553 & 34.1462 & -636 & 105 & 120 & 1.14 & Martinez and Cochran1989 \\
49 & 27.2138 & 35.2327 & -687 & 112 & 114 & 1.02 & Martinez and Cochran1989 \\
50 & 26.9625 & 34.6848 & -1065 & 123 & 111 & 0.9 & Martinez and Cochran1989 \\
51 & 26.7675 & 34.1898 & -681 & 100 & 111 & 1.11 & Martinez and Cochran1989 \\
52 & 26.7587 & 34.1643 & -666 & 98 & 111 & 1.13 & Martinez and Cochran1989 \\
53 & 26.7708 & 34.2087 & -654 & 96 & 106 & 1.1 & Martinez and Cochran1989 \\
54 & 26.7972 & 34.2875 & -717 & 96 & 100 & 1.04 & Martinez and Cochran1989 \\
55 & 26.7793 & 34.2502 & -711 & 83 & 88 & 1.06 & Martinez and Cochran1989 \\
56 & 26.9648 & 34.6643 & -980 & 70 & 63 & 0.9 & Martinez and Cochran1989 \\
57 & 27.0803 & 34.7338 & -1431 & 64 & 56 & 0.88 & Martinez and Cochran1989 \\
58 & 26.7668 & 34.1632 & -709 & 0 & 0 & 1.13 & Martinez and Cochran1989 \\
59 & 27.1407 & 35.0015 & -996 & 0 & 0 & 0.95 & Martinez and Cochran1989 \\
60 & 27.0478 & 34.7422 & -1313 & 0 & 0 & 0.88 & Martinez and Cochran1989 \\
\hline
\end{tabular}

\section{Data and Methodology}

In this study, the earthquake frequency distributions from the reviewed catalogue of the Egyptian National Seismic Network (ENSN) were used to explain the distribution of the seismicity over the area. Our study concerns a moderate earthquake that occurred on the 16th June 2020, with magnitude $(\mathrm{ML}=5.2)$ and hit the Northern Red Sea region, Egypt, and was felt throughout the Hurghada and Sharm El-Sheikh cities and the surrounding areas, without any damages.

In this study, the time-series of satellite remote sensing data (SST) products of the Moderate Resolution Imaging Spectroradiometer (MODIS, Level-3) are used over the Northern Red Sea region to examine the changes in oceanographic conditions before and after the 16th June 2020 earthquake. The SST MODIS data generated by the Ocean Data Processing System (ODPS) were derived from the MODIS sensors onboard the NASA Terra and Aqua platforms since November 2000. SST MODIS data products are acquired from the NASA Ocean Color Web (http://oceancolor.gsfc. nasa.gov) that have been aggregated/projected onto a welldefined spatial grid with mapping data.

In the present study, the MODIS AQUA SST Daytime/Nighttime daily products were extracted with Level-3 with $4 \mathrm{~km}$ spatial resolution. The SST images acquired at a wavelength of $11 \mu \mathrm{m}$ were utilized to find the correlation between the thermal anomalies and the seismic activities before and after the 16th June 2020, Northern Red Sea earthquake for two periods (two weeks before and five days after the earthquake). Standard deviation ( $\sigma$ ) of the mean LST values was identified, and $\pm 2 \sigma$ (95\% confidence level) interval was considered as an anomaly indicator measure. The upper bound (UB) and the lower bound (LB) were calculated by the following equations:

$\mathrm{UB}=$ mean value $+2 \sigma$

$\mathrm{LB}=$ mean value $-2 \sigma$

The SST continuity algorithm is applied for the Daytime/Nighttime observations. It is based on a modified version of the nonlinear SST algorithm (NLSST) of Walton et al., [51] that uses the empirical coefficients derived from the regression of collocated in situ and satellite measurements. This algorithm provides the product continuity between NASA's current and future IR sensors and the heritage Pathfinder SST from AVHRRs.

For heat flow data, three profiles of heat flow composed of (stations) are used in this study. As part of this survey, 197 temperature gradient measurements were used for thermal conductivity determinations [52]. The heat flow stations were organized into three perpendicular profiles $\left(60^{\circ}\right)$ to the red sea rift and separated by $35 \mathrm{~km}$ from each other along the Red Sea rift. Each profile consists of 60-70 individual stations separated by $2 \mathrm{~km}$ apart. This pattern provides three independent measures of the heat flow variations across the rift. The locations of the heat flow profiles are shown in Fig. 2, and their measurements are given in Tables 1,2, and 3.

The heat flow measurements indicate that the conductivity is characterized by low values ranging from 0.8 to $1.15 \mathrm{~W} \mathrm{~m}^{-1} \mathrm{~K}^{-1}$; these values are compatible with volcanic rocks within typical sections [53] of the lowest mean thermal conductivity values (Tuff or Andesite), which associated with high porosity. Therefore, the SST anomaly patterns overly- 
Table 3 Heat Flow Measurements at Profile 3 (Southern Line)

\begin{tabular}{|c|c|c|c|c|c|c|c|}
\hline No. of the Site & Latitude & Longitude & Elevation & Gradient & Heat flow & Conductivity & Reference \\
\hline \multirow[t]{2}{*}{1} & 26.8877 & 35.4823 & -560 & 290 & 293 & 0.88 & Martinez and Cochran1989 \\
\hline & 26.6697 & 34.9905 & -1165 & 335 & 291 & 0.88 & Martinez and Cochran 1989 \\
\hline 3 & 26.6862 & 35.0467 & -1160 & 326 & 280 & 0.89 & Martinez and Cochran1989 \\
\hline 4 & 26.6952 & 35.0657 & -1147 & 311 & 264 & 0.89 & Martinez and Cochran1989 \\
\hline 5 & 26.6112 & 34.8832 & -948 & 284 & 256 & 0.88 & Martinez and Cochran1989 \\
\hline 6 & 26.6538 & 34.95 & -1205 & 275 & 242 & 0.95 & Martinez and Cochran 1989 \\
\hline 7 & 26.6377 & 34.9163 & -1180 & 272 & 242 & 0.94 & Martinez and Cochran1989 \\
\hline 8 & 26.6553 & 34.968 & -1207 & 271 & 238 & 0.89 & Martinez and Cochran1989 \\
\hline 9 & 26.6457 & 34.9332 & -1250 & 264 & 235 & 0.89 & Martinez and Cochran 1989 \\
\hline 10 & 26.6383 & 34.8952 & -945 & 255 & 230 & 0.88 & Martinez and Cochran 1989 \\
\hline 11 & 26.6357 & 34.8972 & -965 & 254 & 229 & 0.94 & Martinez and Cochran 1989 \\
\hline 12 & 26.464 & 34.4893 & -767 & 230 & 225 & 0.96 & Martinez and Cochran1989 \\
\hline 13 & 26.6857 & 35.0417 & -1165 & 259 & 223 & 0.92 & Martinez and Cochran1989 \\
\hline 14 & 26.7808 & 35.2498 & -957 & 244 & 222 & 0.92 & Martinez and Cochran1989 \\
\hline 15 & 26.7368 & 35.1693 & -1030 & 248 & 218 & 0.9 & Martinez and Cochran1989 \\
\hline 16 & 26.7595 & 35.2118 & -952 & 242 & 218 & 0.89 & Martinez and Cochran1989 \\
\hline 17 & 26.755 & 35.1965 & -985 & 239 & 215 & 0.95 & Martinez and Cochran1989 \\
\hline 18 & 26.4618 & 34.5035 & -780 & 219 & 212 & 1.03 & Martinez and Cochran1989 \\
\hline 19 & 26.6062 & 34.8408 & -960 & 233 & 210 & 0.93 & Martinez and Cochran 1989 \\
\hline 20 & 26.8885 & 35.5175 & -522 & 206 & 210 & 0.94 & Martinez and Cochran 1989 \\
\hline 21 & 26.7685 & 35.2333 & -952 & 230 & 209 & 0.91 & Martinez and Cochran1989 \\
\hline 22 & 26.5078 & 34.6255 & -896 & 223 & 205 & 0.96 & Martinez and Cochran1989 \\
\hline 23 & 26.7323 & 35.148 & -1030 & 231 & 203 & 0.96 & Martinez and Cochran1989 \\
\hline 24 & 26.7488 & 35.1833 & -1018 & 228 & 203 & 0.9 & Martinez and Cochran1989 \\
\hline 25 & 26.5875 & 34.8067 & -930 & 223 & 201 & 0.91 & Martinez and Cochran1989 \\
\hline 26 & 26.801 & 35.3155 & -778 & 207 & 195 & 0.88 & Martinez and Cochran1989 \\
\hline 27 & 26.6017 & 34.825 & -972 & 216 & 194 & 0.95 & Martinez and Cochran 1989 \\
\hline 28 & 26.537 & 34.6947 & -830 & 211 & 192 & 0.88 & Martinez and Cochran 1989 \\
\hline 29 & 26.5775 & 34.7923 & -972 & 211 & 192 & 0.9 & Martinez and Cochran 1989 \\
\hline 30 & 26.717 & 35.1257 & -1090 & 216 & 188 & 1.08 & Martinez and Cochran1989 \\
\hline 31 & 26.527 & 34.6547 & -844 & 196 & 178 & 0.94 & Martinez and Cochran 1989 \\
\hline 32 & 26.5525 & 34.7383 & -962 & 192 & 175 & 1 & Martinez and Cochran1989 \\
\hline 33 & 26.5428 & 34.7182 & -815 & 191 & 174 & 0.97 & Martinez and Cochran1989 \\
\hline 34 & 26.7058 & 35.103 & -1091 & 200 & 172 & 0.92 & Martinez and Cochran1989 \\
\hline 35 & 26.406 & 34.386 & -815 & 162 & 172 & 0.97 & Martinez and Cochran 1989 \\
\hline 36 & 26.7043 & 35.0852 & -1091 & 201 & 171 & 0.99 & Martinez and Cochran1989 \\
\hline 37 & 26.5307 & 34.6772 & -820 & 185 & 168 & 1.02 & Martinez and Cochran1989 \\
\hline 38 & 26.568 & 34.7755 & -928 & 183 & 167 & 0.93 & Martinez and Cochran1989 \\
\hline 39 & 26.8183 & 35.3315 & -735 & 173 & 164 & 0.97 & Martinez and Cochran 1989 \\
\hline 40 & 26.8793 & 35.482 & -560 & 158 & 158 & 1.01 & Martinez and Cochran1989 \\
\hline 41 & 26.6095 & 34.8597 & -922 & 172 & 155 & 0.98 & Martinez and Cochran1989 \\
\hline 42 & 26.4177 & 34.4047 & -813 & 149 & 155 & 1.04 & Martinez and Cochran1989 \\
\hline 43 & 26.7843 & 35.2675 & -923 & 167 & 153 & 1.05 & Martinez and Cochran1989 \\
\hline 44 & 26.7875 & 35.2957 & -763 & 160 & 149 & 0.99 & Martinez and Cochran1989 \\
\hline 45 & 26.832 & 35.3818 & -700 & 154 & 148 & 1.01 & Martinez and Cochran1989 \\
\hline
\end{tabular}


Table 3 continued

\begin{tabular}{|c|c|c|c|c|c|c|c|}
\hline No. of the Site & Latitude & Longitude & Elevation & Gradient & Heat flow & Conductivity & Reference \\
\hline 46 & 26.424 & 34.4245 & -812 & 144 & 148 & 0.98 & Martinez and Cochran1989 \\
\hline 47 & 26.8875 & 35.502 & -507 & 145 & 146 & 1 & Martinez and Cochran1989 \\
\hline 48 & 26.4503 & 34.478 & -810 & 146 & 145 & 1.02 & Martinez and Cochran1989 \\
\hline 49 & 26.4707 & 34.5373 & -875 & 149 & 142 & 1.14 & Martinez and Cochran1989 \\
\hline 50 & 26.822 & 35.3583 & -714 & 148 & 142 & 1.02 & Martinez and Cochran1989 \\
\hline 51 & 26.5612 & 34.7573 & -885 & 154 & 140 & 0.9 & Martinez and Cochran1989 \\
\hline 52 & 26.4867 & 34.5678 & -980 & 146 & 136 & 1.11 & Martinez and Cochran1989 \\
\hline 53 & 26.4667 & 34.5238 & -750 & 139 & 133 & 1.13 & Martinez and Cochran1989 \\
\hline 54 & 26.4393 & 34.4647 & -814 & 132 & 132 & 1.1 & Martinez and Cochran1989 \\
\hline 55 & 26.4338 & 34.4432 & -784 & 125 & 126 & 1.04 & Martinez and Cochran1989 \\
\hline 56 & 26.3968 & 34.3643 & -699 & 115 & 122 & 1.06 & Martinez and Cochran1989 \\
\hline 57 & 26.8385 & 35.3942 & -685 & 125 & 121 & 0.9 & Martinez and Cochran1989 \\
\hline 58 & 26.8655 & 35.4668 & -574 & 119 & 119 & 0.88 & Martinez and Cochran1989 \\
\hline 59 & 26.8438 & 35.411 & -623 & 116 & 114 & 1.13 & Martinez and Cochran1989 \\
\hline 60 & 26.8527 & 35.4295 & -588 & 113 & 111 & 0.95 & Martinez and Cochran1989 \\
\hline 61 & 26.3865 & 34.3472 & -538 & 95 & 104 & 0.88 & Martinez and Cochran1989 \\
\hline 62 & 26.8582 & 35.4472 & -585 & 101 & 100 & 0.9 & Martinez and Cochran1989 \\
\hline 63 & 26.496 & 34.5922 & -808 & 107 & 98 & 1.08 & Martinez and Cochran1989 \\
\hline 64 & 26.3792 & 34.3272 & -425 & 62 & 69 & 0.94 & Martinez and Cochran1989 \\
\hline 65 & 26.7423 & 35.1647 & -1031 & 0 & 0 & 1 & Martinez and Cochran1989 \\
\hline 66 & 26.4808 & 34.5807 & -975 & 0 & 0 & 0.97 & Martinez and Cochran1989 \\
\hline 67 & 26.621 & 34.8762 & -1040 & 0 & 0 & 0.92 & Martinez and Cochran1989 \\
\hline 68 & 26.707 & 35.0858 & -1249 & 0 & 0 & 0.97 & Martinez and Cochran1989 \\
\hline 69 & 26.5248 & 34.6588 & -844 & 0 & 0 & 0.99 & Martinez and Cochran1989 \\
\hline 70 & 26.7843 & 35.268 & -923 & 0 & 0 & 1.02 & Martinez and Cochran1989 \\
\hline
\end{tabular}

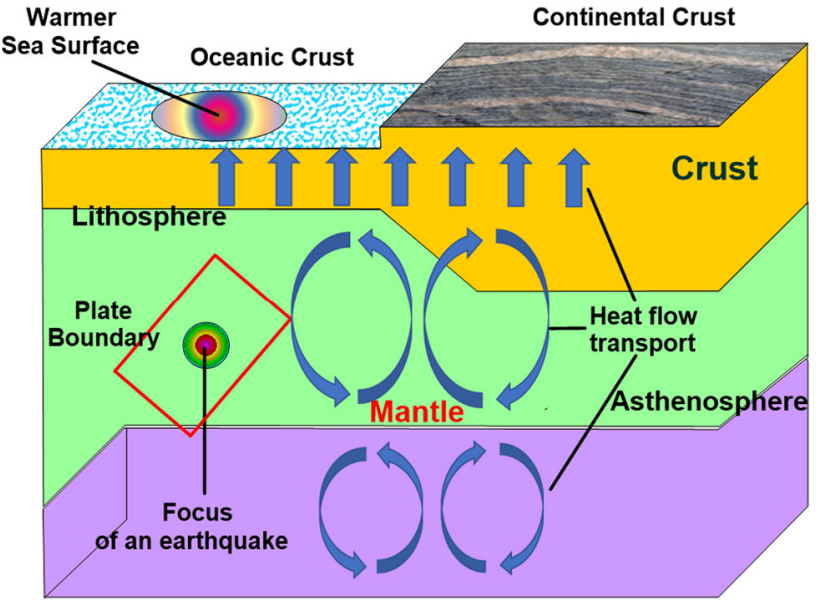

Fig. 2 Shows a specified diagram that links the observed heat flow and sea surface temperatures with the processes of active tectonics

ing earthquake events are hypothesized to result from the increased heat emission from seafloor volcanic extrusions and associated hydrothermal venting.

\section{Results and Discussion}

The results of spatial resolution of the Daytime SST data indicated that SST variations were observed and increased anomalously by covering a large area of warm water close to the epicenter within $60 \mathrm{~km}$ impact area on the 12th June, five days before the earthquake. However, dramatic decreases were observed on the 13th and 14th June 2020, then increased on the 15th June, one day before the earthquake (Fig. 3). This anomaly could be related to thermodynamic processes within the earth's crust, as thermal radiation anomaly around the epicenter $60 \mathrm{~km}$ impact area. Figure 4 shows the spatial resolution of the Nighttime SST data, indicating that a low anomaly is observed around the epicenter on the 13th June and followed by a high value close to the epicenter on the 14 th and the 15thJune 2020. Therefore, the spatial resolution of SST Daytime/Nighttime is consistent with each other.

The statistical analyses presented in Fig. 5 show the SST Daytime \& Nighttime values that were extracted from the images, based on the $60 \mathrm{~km}$ impact area around the epicenter. Based on the $\pm 2 \sigma$ rule, two anomalous days in the Daytime observed on the 04th June were characterized by the lowest 


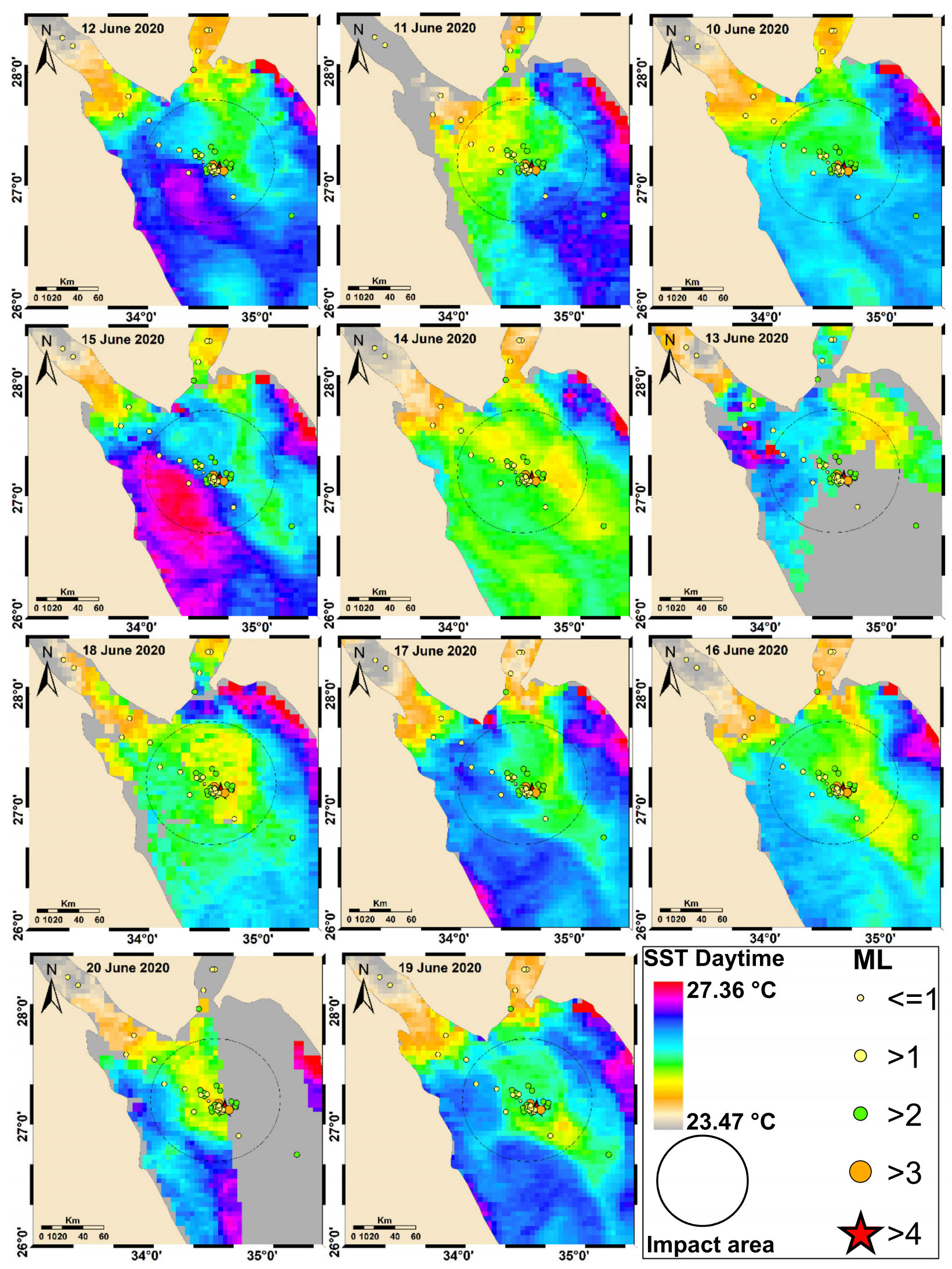

Fig. 3 Daytime LST selected images utilized before and after the occurrence of the Northern Red Sea earthquake. The black circle denotes the impact area around epicenters 


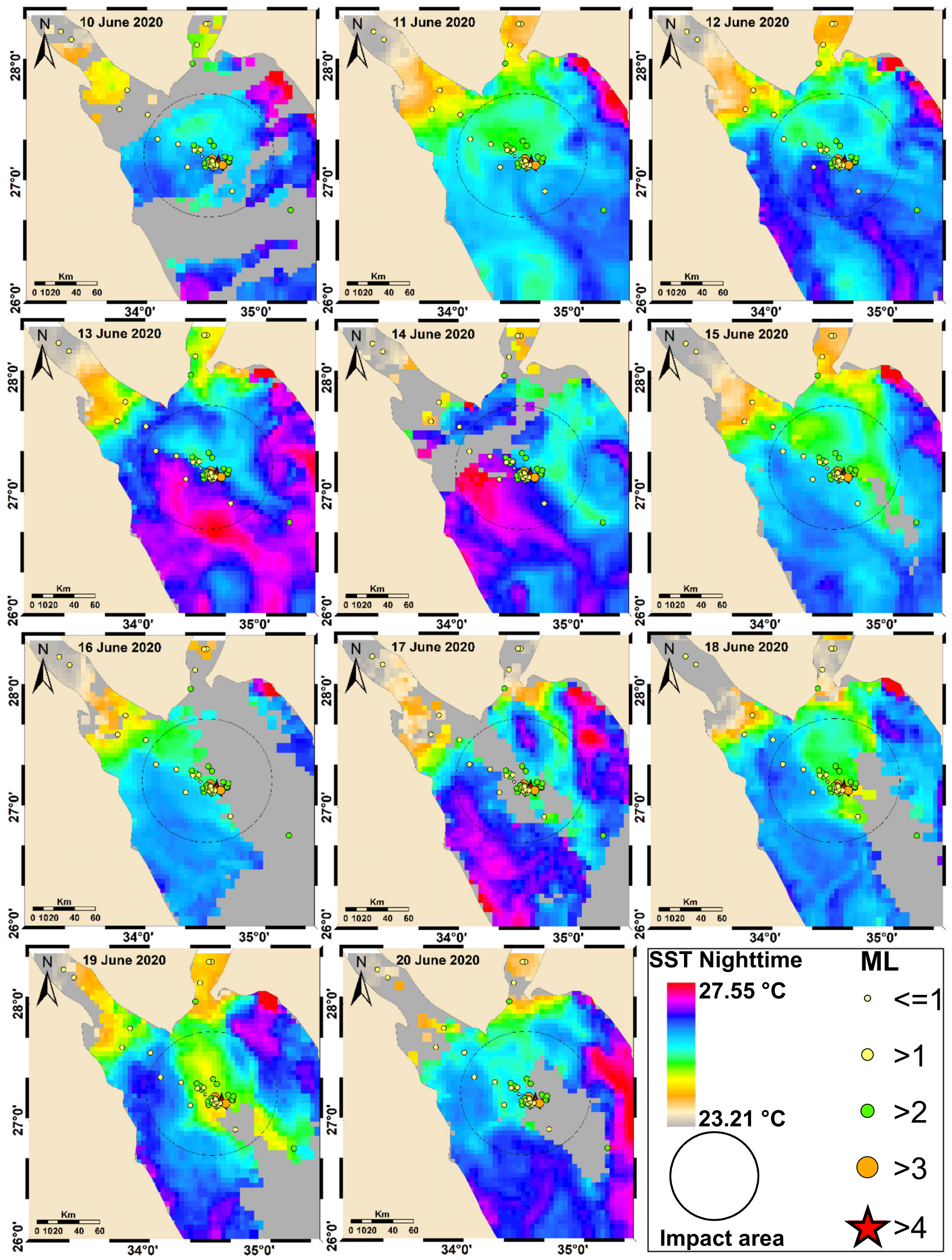

Fig. 4 Nighttime LST for some selected images, utilized before and after the Northern Red Sea earthquake. The black circle denotes the impact area around epicenters 


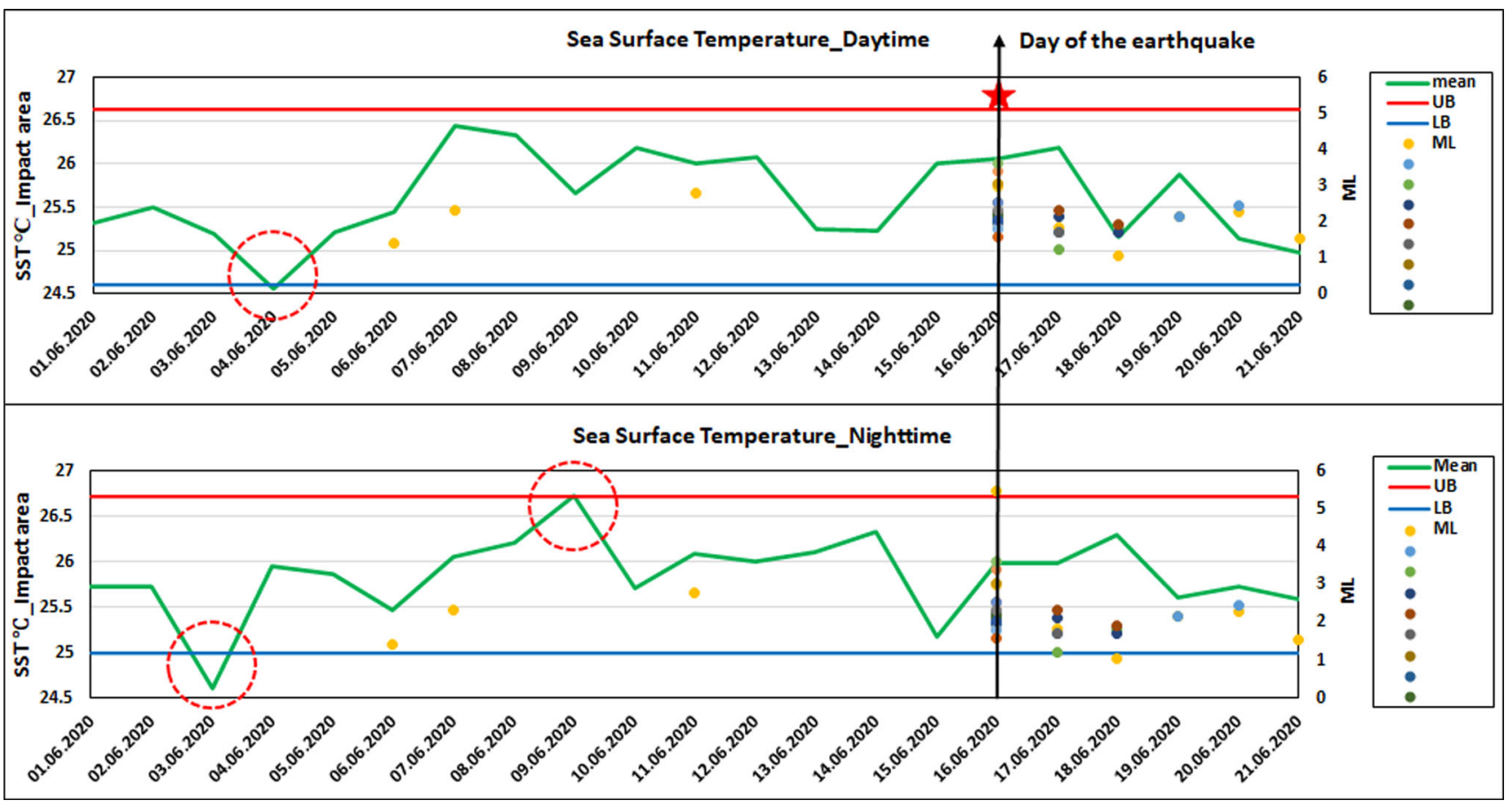

Fig. 5 Statistical analysis of the LST_Daytime\&Nighttime observation with seismic data before and after the 16th June 2020 Northern Red Sea earthquake. The red circle denotes the thermal anomaly

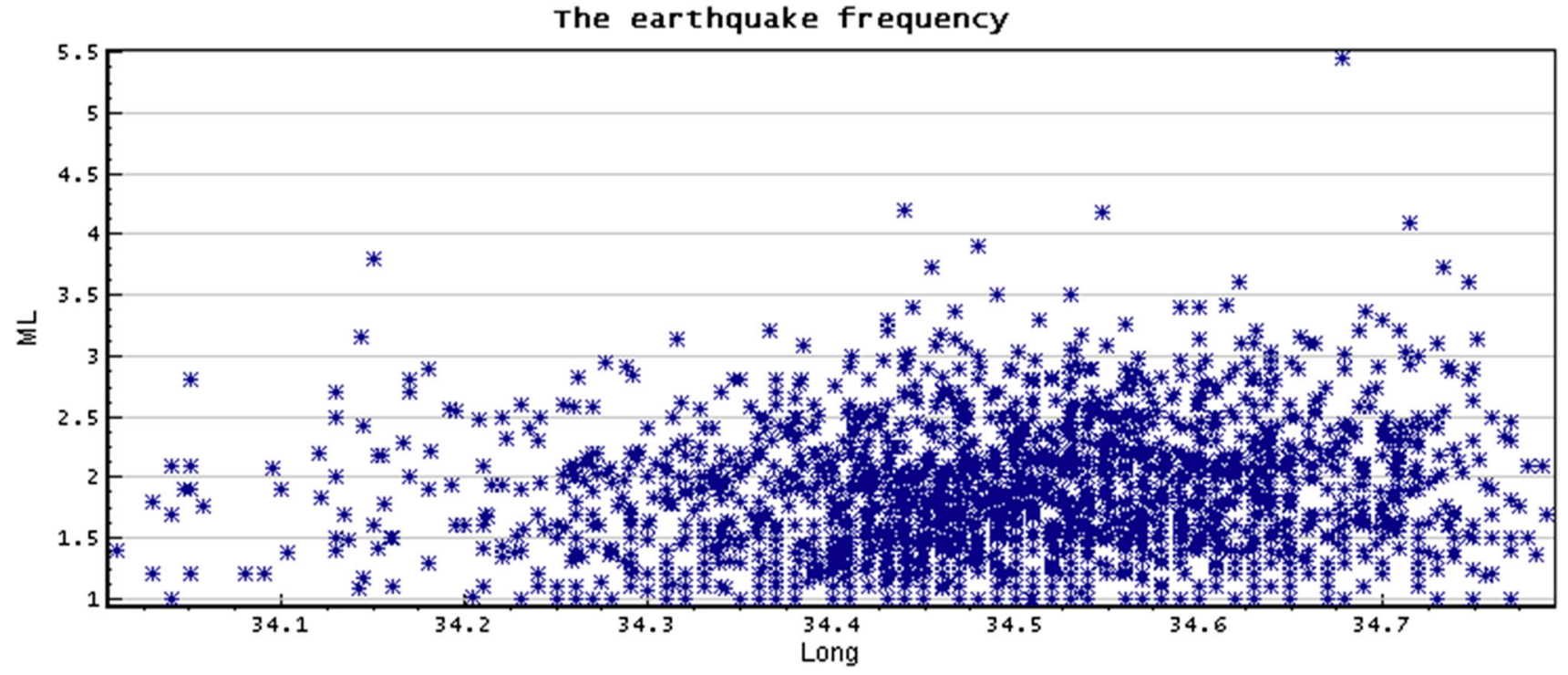

Fig. 6 Statistical analysis of the earthquake's frequencies with magnitude sizes in the Northern Red Sea from 1997 to 2020

value, while on the 15 th June indicated by the highest value. The behavior of the mean increases from the 06th June to the earthquakes' day about ten days before the earthquake, which can be considered short-term precursors of the earthquake. The SST in the Daytime seems stable, then decreases due to the energy released by the seismicity.

However, the results of the SST Nighttime analysis indicated that there are three anomalous days observed, one day (03rd June, characterized by negative anomalous) and the other days (the 09th and the 14th June, characterized by positive anomaly). The mean behavior indicates an increase from the 07th June to the 14th June) which is considered a short-term precursor of the earthquake. On the 15 th, the 16 th June (earthquake day), a dramatic decrease occurred after the earthquake. On the other hand, no significant variation in the mean Nighttime SST is observed after the anomalous days. The findings of this study indicate that the thermal anomaly was observed 11 days before the earthquakes. 


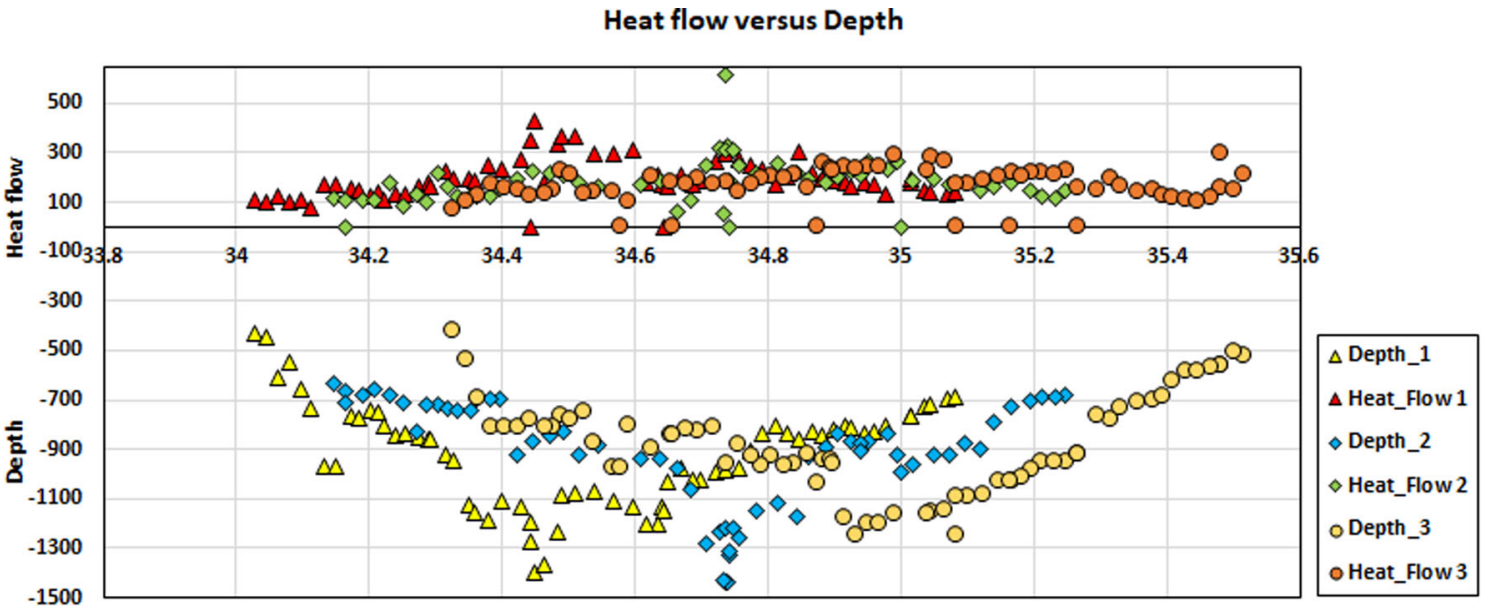

Fig. 7 Statistical analysis of the heat flow measurements with depth for the three profiles 1, 2, and 3 from (north to south) in the Northern Red Sea

Fig. 8 The contour map of heat flow measurements shows that the high values are concentrated at the center of the Red Sea rift, close to the epicenter and the surrounding area

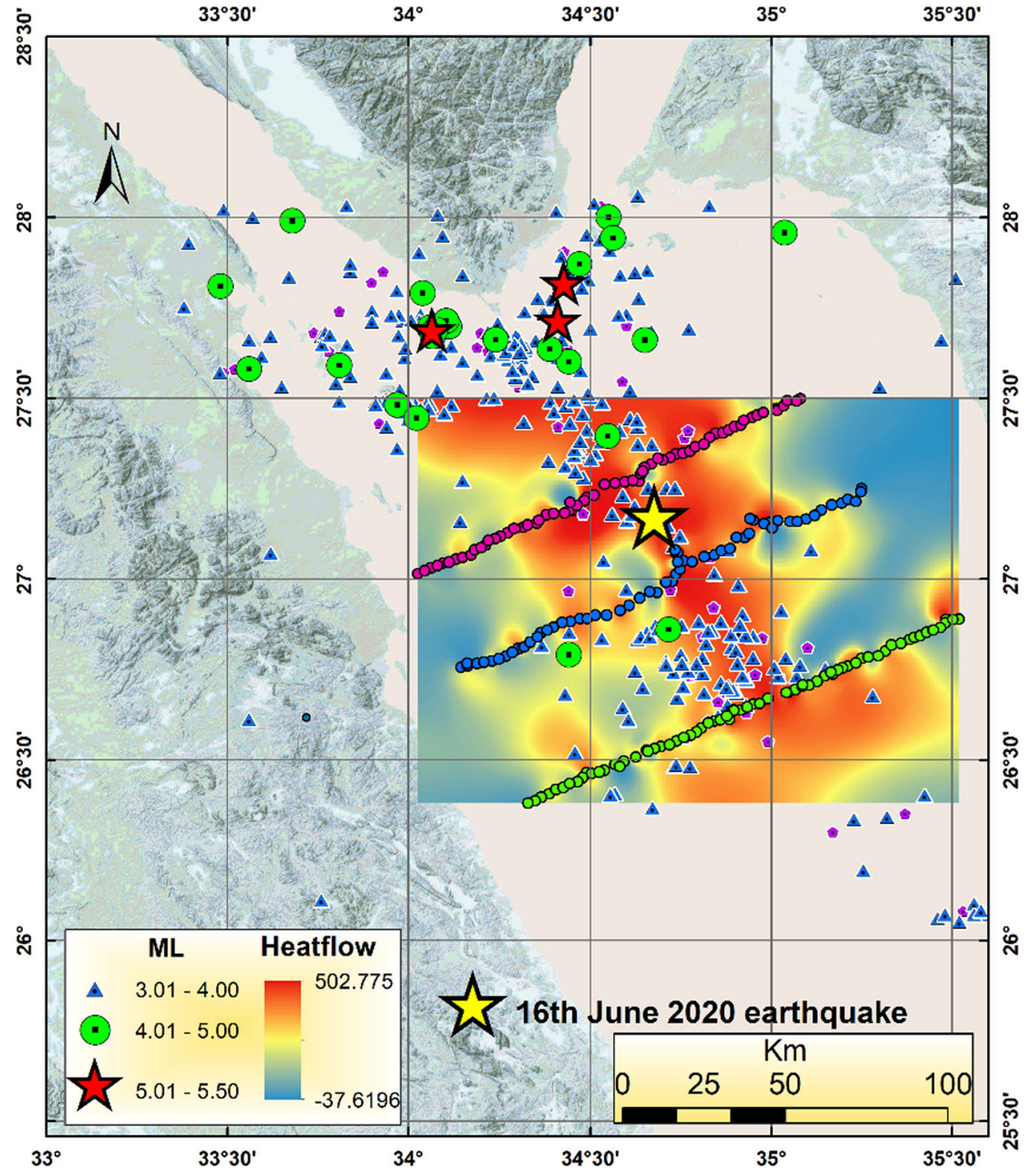




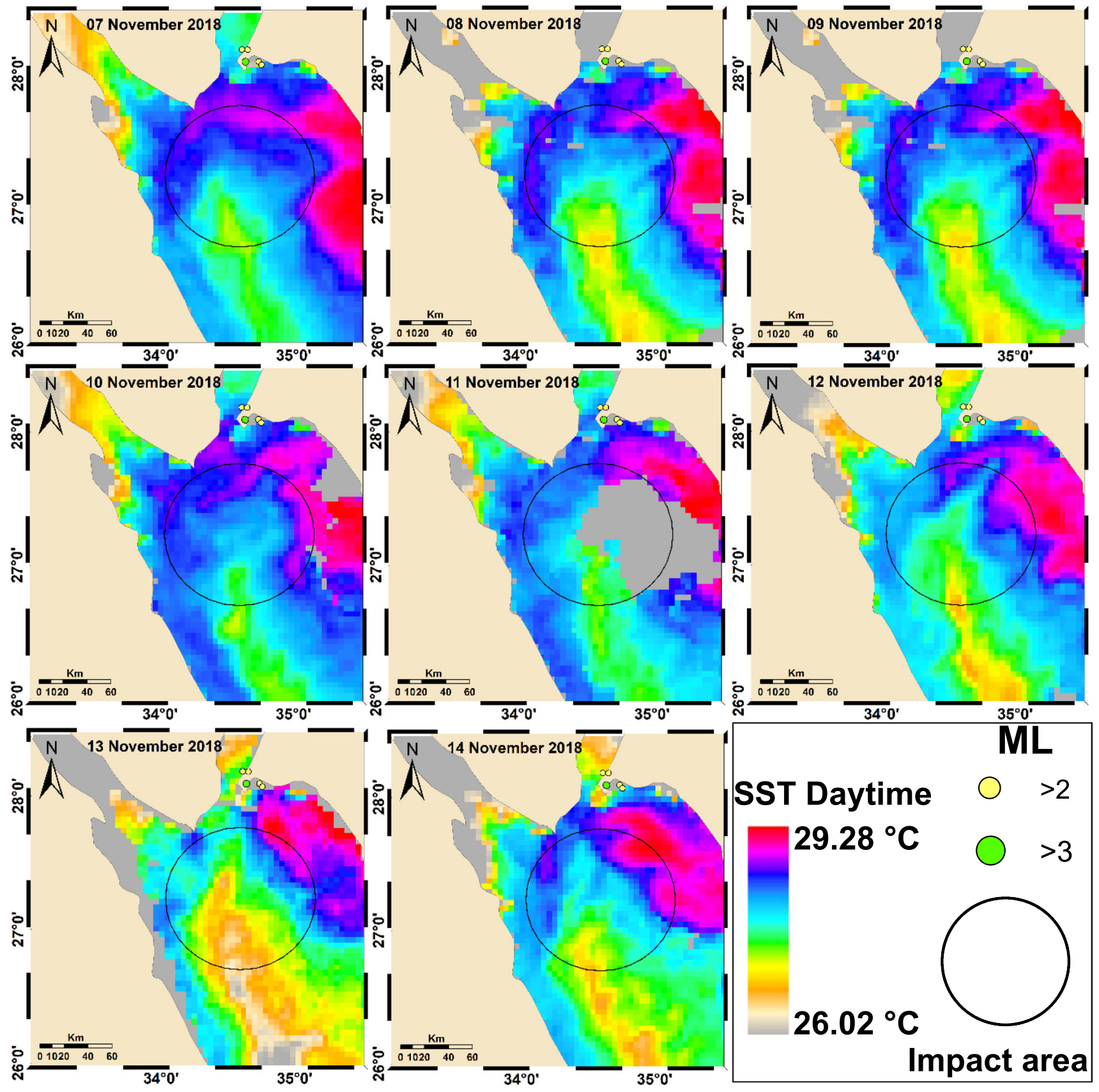

Fig. 9 Daytime SST for some selected images utilized from the 1st November 2018 to the 15th November 2018 (non-seismic year) in the Northern Red Sea. The black circle denotes the impact area

In this context, the Daytime/Nighttime SST analysis indicated that a disturbance occurred during the two weeks preceding the earthquake, which could be considered precursors of the earthquake. Therefore, this finding is consistent and compatible with previous studies [14, 54-57].

Figure 6 indicates the statistical analysis of earthquake frequencies with magnitude size; it is indicated that the peak of the seismicity is concentrated at the center of the rift and decreases on both sides (left and right). These results are con- sistent with the heat flow measurements for the three profiles (Fig. 7), indicating that the maximum values are concentrated in the middle of the profiles, and the heat flow values increase with depth. Moreover, Fig. 8 shows a contour map of the heat flow values with a color gradient. Light blue represents the minimum, and deep red represents the maximum. The spatial pattern of the heat flow in the figure shows that the center of the Red Sea rift is hot while the other sides are cold, indicating that the highest values are also concentrated 


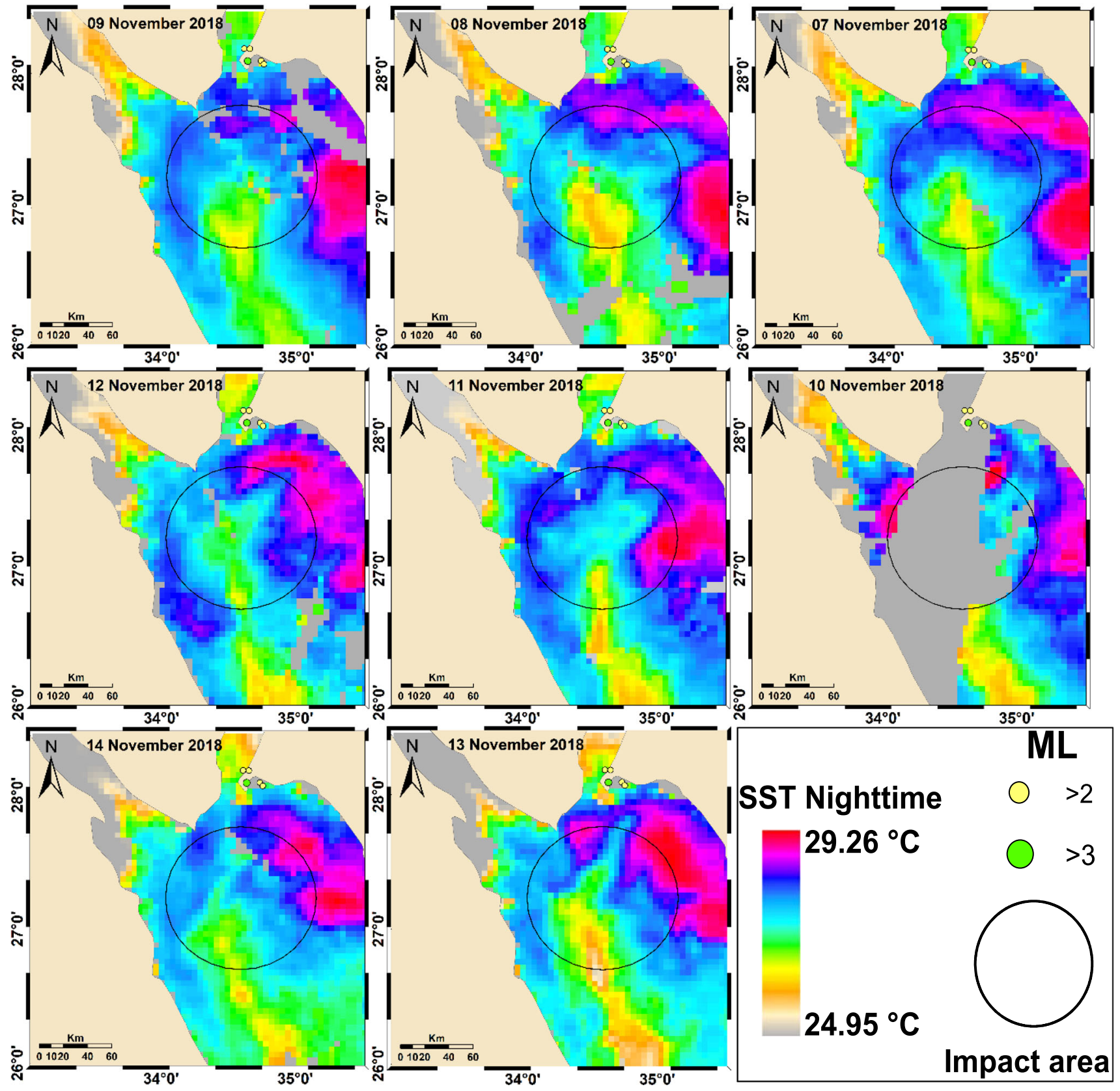

Fig. 10 Nighttime SST for some selected images utilized during the period from 1-15 November 2018 (non-seismic year) in the Northern Red Sea. The black circle denotes the impact area

at the center of the Red Sea rift and close to the epicenter of the earthquake. These findings are consistent with the SST results obtained from satellite data.

\section{Validation of the Results}

We have extracted and analyzed satellite SST data based on the non-seismic year and another event in the same area of study to validate and clarify our results. For the non-seismic year, we have used two weeks of data analysis during 1-15
November of 2018, which is characterized by no earthquakes occurring in the area of study (non-seismic activity). The results indicated that no thermal anomaly is observed (Figs. 9, 10 , and 11) compared to the year 2020, in which the earthquake has occurred and is followed by a few swarms (Figs. 3, 4 , and 5). For the second event in the same study area, we have extracted and analyzed satellite data before and after an earthquake occurred on the 03rd June 2004 with ML = 4.2 close the study area, during the 15th May-the 08th June 2004. The results indicate that a disturbance in surface temperature has been noticed and a significant thermal anomaly 
Sea Surface Temperature_Daytime
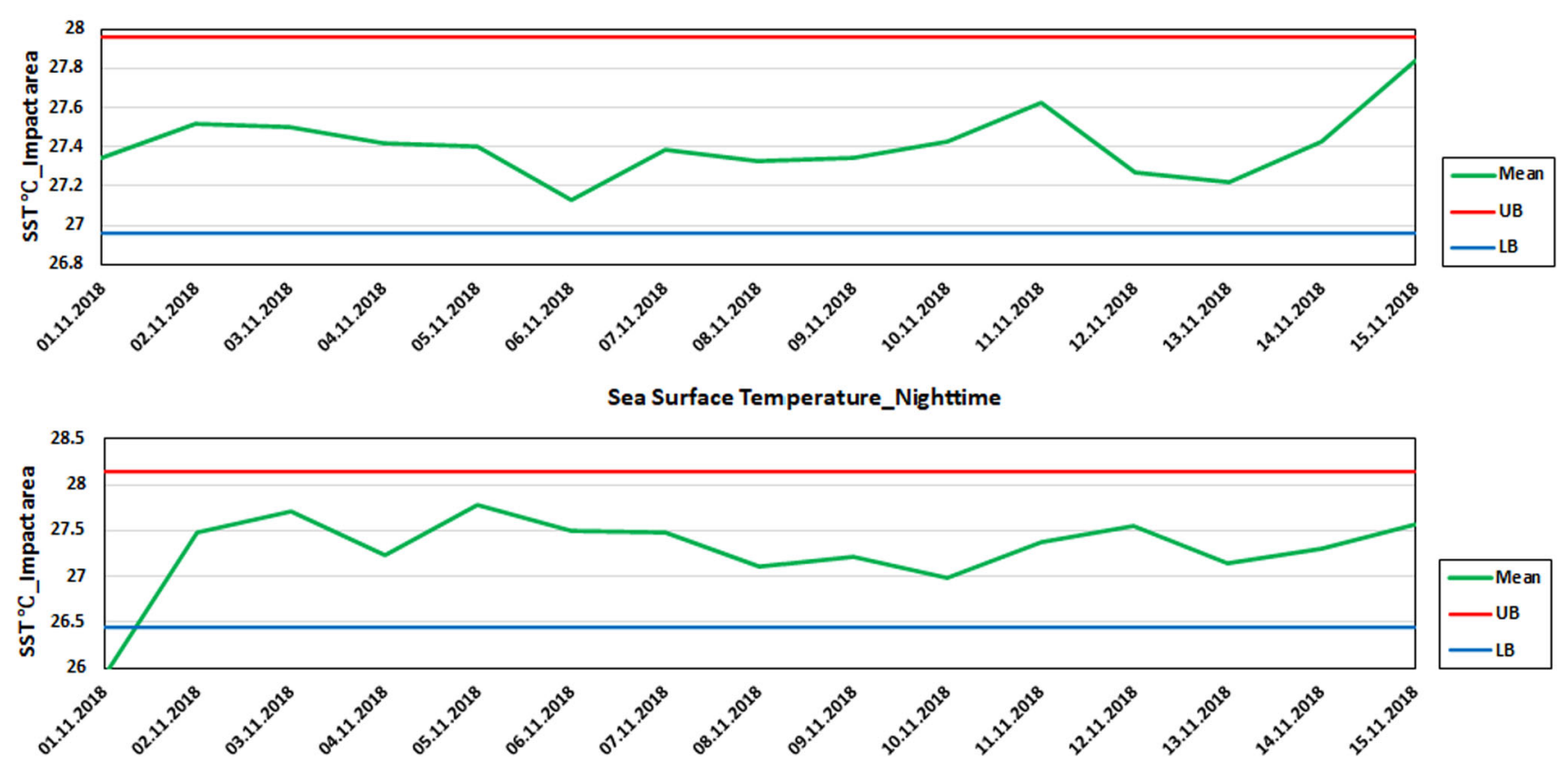

Fig. 11 Statistical analysis of the SST_Daytime\&Nighttime observation during the period from 1-15 November 2018 in the same area (Northern Red Sea). No thermal anomaly is observed

is observed on 17th and 23rd May 2004 in Daytime and the 15 th, the 17th, the 19th, the 22nd, and the 23rd May 2004 in Nighttime about 10-17 days before the earthquake occurrence as shown in Figs. 12, 13, and 14.

Based on the SST analysis, we rearranged all figures and text based on the new results, which were provided in their sections. The results generally confirm the precursory behaviors of the SST for another event and compared to the same area of the non-seismic year.

\section{Conclusions}

The active seismic zones in Egypt occur in the northern part of the country, including the Northern Red Sea, the Gulf of Suez, the Gulf of Aqaba, the Cairo-Suez district, Southwest of Greater Cairo (Dahshour area), and the Eastern Mediterranean region, as well as the low seismic activities in the central and southern parts of Egypt. The earthquakes range from small to moderate magnitudes, except the significant historical earthquakes that been occurred in the Northeast of Egypt (e.g., Shadwan earthquake in 1969, with $\mathrm{Mb}=6$ and the Aqaba earthquake in 1995, with $\mathrm{Mb}=7$ ). The frequency distributions presumed from the reviewed catalogue indicated that the peak of the seismicity is concentrated close to the center of the Red Sea rift. Our study concerns the recent earthquake on the 16th June 2020 in the Northern Red Sea.

This study examines the change in the local oceanographic conditions of the SST data over the Northern Red Sea region before and after the 16th June 2020 Hurghada earthquake, based on satellite remote sensing data provided by NASA Ocean Color. This study used three heat flow profiles 197 temperature gradient measurements for thermal conductivity determinations [50].

The results of spatial resolution of the Daytime SST data indicated that SST variations were observed and increased anomalously by covering a large area of warm water close to the epicenter, within $60 \mathrm{~km}$ impact area on the 12th June 2020 , followed by dramatic decreases on the 13 th and the 14th June 2020. Then, it increased on the 15th June, one day before the earthquake; this anomaly could be related to thermodynamic processes within the earth's crust, as thermal radiation anomaly around the epicenter $60 \mathrm{~km}$ impact area. While the spatial resolution of Nighttime SST data indicated that a low anomaly was observed on the 13th June, followed by a high value close the epicenter on the 14th and 15 th June 2020. Therefore, the spatial resolution of the SST Daytime/Nighttime is almost consistent with each other.

The statistical analyses based on the $\pm 2 \sigma$ rule demonstrate that two anomalous days in the Daytime were observed on the 04th June with (negative anomaly) and the 15th June with (positive anomaly). The behavior of the mean increases from the 06th June to the earthquakes' day about ten days before the earthquake, which can be considered as short-term precursors of the earthquake. After the earthquake occurrence, the Daytime SST seems stable, then decreases due to the energy released by the seismicity. 
Fig. 12 Daytime SST for some selected images, utilized before and after the second event (the 03rd June 2004) in the Northern Red Sea. The black circle denotes the impact area around epicenters

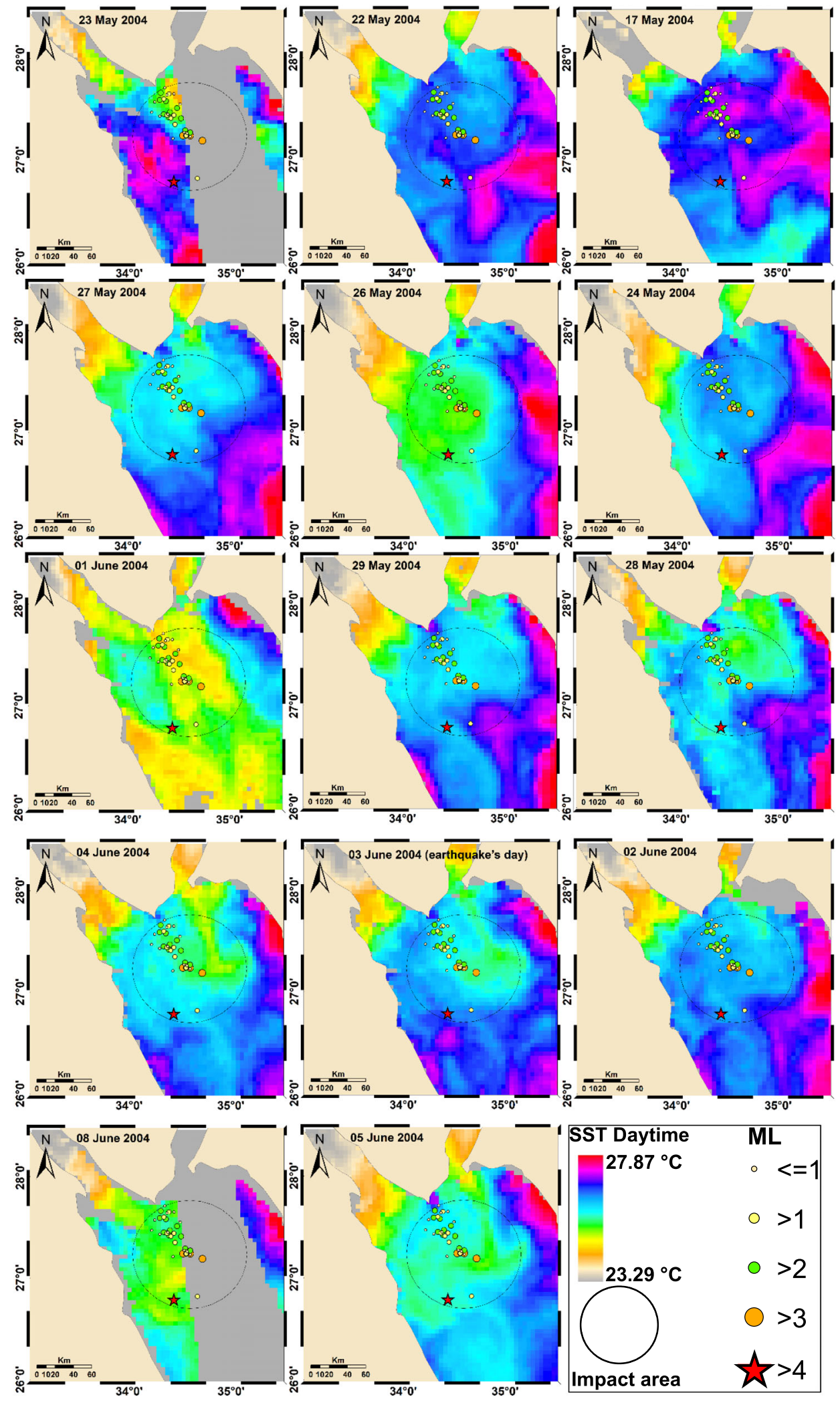

While the Nighttime SST results indicated that three anomalous days were observed, one day (the 03rd June with negative anomaly) and the other days (the 09th and the 14th
June with positive anomaly). The mean behavior increases from the 07th June to the 14th June, which can be also considered as a short-term precursor of the earthquake. While 
Fig. 13 Nighttime SST for some selected images, utilized before and after the second event (the 03rd June 2004) in the Northern Red Sea. The black circle denotes the impact area around epicenters

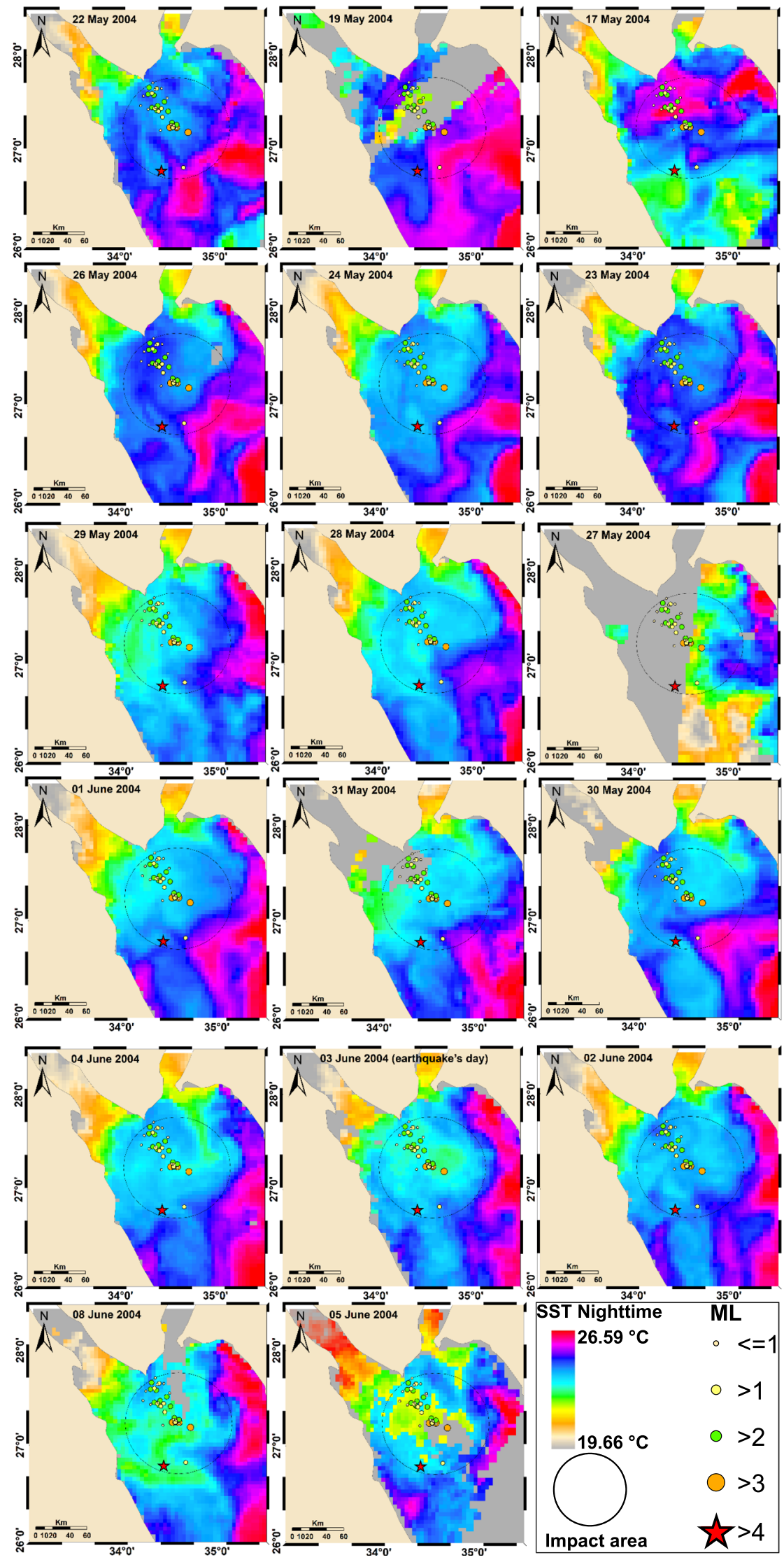




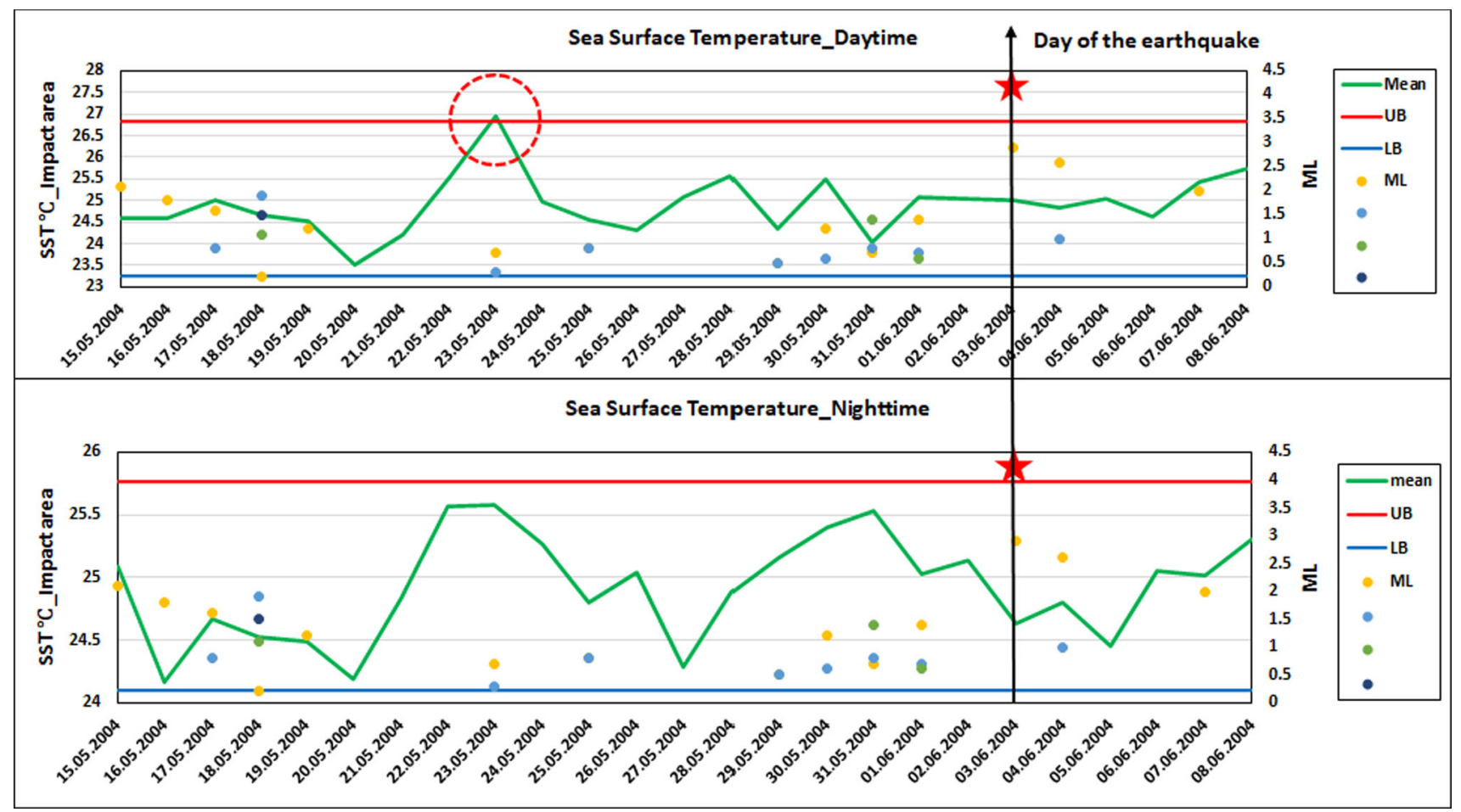

Fig. 14 Statistical analysis of the SST_Daytime\&Nighttime observation with seismic data before and after the 03rd June 2004 earthquake in the same area (Northern Red Sea). The red circle denotes the thermal anomaly

on the 16th June (the earthquakes' day) and after, a dramatic decrease occurred. On the other hand, no significant variation in the mean Nighttime SST is observed after the anomalous days. The findings of this study indicate that the thermal anomaly is observed two weeks before the earthquake. Therefore, this finding is consistent and compatible with previous studies [14, 54-57].

We have extracted and analyzed satellite SST data based on the non-seismic year and another event in the same area of study to validate and clarify our results. For the non-seismic year, we have used data analysis during the period 1-15 November 2018; no earthquakes occurred in the area of study (non-seismic activity). The results indicated that no thermal anomaly is observed compared to the year 2020, in which the earthquake has occurred and followed by a few swarms. For the second event in the same area of study, we have extracted and analyzed satellite data before and after an earthquake has occurred on the 03rd June 2004 with ML $=4.2$ from the 15th May to the 08th June 2004; the results indicated that a disturbance in surface temperature has been noticed and a significant thermal anomaly is observed on the 17 th and the 23rd May 2004 for Daytime and 15th, 17th, 19th, 22nd and 23rd May 2004 for Nighttime about 10-17 days before the earthquake occurrence as it shown in Figs. 12, 13, and 14. The results generally confirm the precursory behaviors of the SST for another event and compared to the same area of the non-seismic year.
Moreover, the statistical analysis of the earthquake frequencies versus magnitude sizes indicates that the peak of the seismicity is concentrated at the center of the Red Sea rift and decreases toward both sides (left and right). These results are consistent with the heat flow measurements carried out by [49]. These findings suggest that seismic activity plays an important role in the heat flow and energy fluxes from the epicenter to the surrounding area. $[58,59]$ confirmed that the geologic faults and the large vertical cracks play an important role in heat energy (thermal) and fluid transfers in the hydrothermal systems.

Finally, the results of this study are beneficial for seismologists. It provides a guide on how the SST anomalies can be considered a precursor of the undersea earthquake (offshore). In this research, spatial and statistical analyses achieved significant results. However, to get better for a robust solution in terms of multi-earthquake precursors, it is necessary to launch a thorough search for the anomalies of sea surface parameters such as SST, sea surface winds (SSW), and sea surface pressure (SSP), or concerning multi-earthquakes precursors, such as the total electron content (TEC) and outgoing longwave radiation (OLR) over the Northern Red Sea rift during the tectonic activities with different periods.

Acknowledgements The authors would like to thank the Egyptian National Seismological Network (ENSN) for providing the seismological data. Also, we would like to thank the Ocean Biology Processing Group (OBPG) at NASA's Goddard Space Flight Center for providing 
us with MODIS SST data, which can be downloaded directly from the https://oceancolor.gsfc.nasa.gov/ website.

Funding Open access funding provided by The Science, Technology \& Innovation Funding Authority (STDF) in cooperation with The Egyptian Knowledge Bank (EKB).

Open Access This article is licensed under a Creative Commons Attribution 4.0 International License, which permits use, sharing, adaptation, distribution and reproduction in any medium or format, as long as you give appropriate credit to the original author(s) and the source, provide a link to the Creative Commons licence, and indicate if changes were made. The images or other third party material in this article are included in the article's Creative Commons licence, unless indicated otherwise in a credit line to the material. If material is not included in the article's Creative Commons licence and your intended use is not permitted by statutory regulation or exceeds the permitted use, you will need to obtain permission directly from the copyright holder. To view a copy of this licence, visit http://creativecomm ons.org/licenses/by/4.0/.

\section{References}

1. Bouchon, M.; Durand, V.; Marsan, D.; Karabulut, H.; Schmittbuhl, J.: The long precursory phase of most large interplate earthquakes. Nat. Geosci. 6(4), 299-302 (2013)

2. Qiang, Z.J.; Xu, X.D.; Dian, C.G.: Satellite infrared thermoanomaly: earthquake imminent precursor. Chin. Sci. Bull. (in Chinese) 35(17), 1324-1327 (1990)

3. Tronin, A.A.: Satellite thermal survey a new tool for the study of seismo active regions. Int. J. Remote Sens. 17(8), 1439-1455 (1996). https://doi.org/10.1080/01431169608948716

4. Tronin, A.A.: Thermal IR satellite sensor data application for earthquake research in China. Int. J. Remote Sens. 21(16), 3169-3177 (2000). https://doi.org/10.1080/01431160050145054

5. Tronin, A.A.: Remote sensing and earthquakes: a review. Phys. Chem. Earth Parts A/B/C 31(4), 138-142 (2006). https://doi.org/ 10.1016/j.pce.2006.02.024

6. Tronin, A.A.; Hayakawa, M.; Molchanov, O.A.: Thermal IR satellite data application for earthquake research in Japan and China. J. Geodyn. 33, 519-534 (2002). https://doi.org/10.1016/S02643707(02)00013-3

7. Ouzounov, D.; Freund, F.: Mid-infrared emission prior to strong earthquakes analyzed by remote sensing data. Adv Space Res 33(3), 268-273 (2004). https://doi.org/10.1016/S02731177(03)00486-1

8. Chen, S.Y.; Ma, J.; Liu, L.Q.; Liu, P.: An enhancive phenomenon of thermal infrared radiation prior to Pakistan earthquake Prog. Nat. Sci. 16, 1487-1490 (2006)

9. Choudhury, S.; Dasgupta, S.; Saraf, A.K.; Panda, S.: Remote sensing observations of pre-earthquake thermal anomalies in Iran. Int. J. Rem. Sens. 27, 4381-4396 (2006). https://doi.org/10.1080/ 01431160600851827

10. Saraf, A.K.; Choudhury, S.: Thermal remote sensing technique in the study of pre-earthquake thermal anomalies. J. Ind Geophy. Union 9, 197-20 (2005)

11. Saraf, A.K.; Rawat, V.; Banerjee, P.: Satellite detection of earthquake thermal infrared precursors in Iran. Nat. Hazards. 47, 119-135 (2008). https://doi.org/10.1007/s11069-007-9201-7

12. Saraf, A.K.; Rawat, V.; Choudhury, S.; Dasgupta, S.; Das, J.: Advances in understanding of the mechanism for generation of earthquake thermal precursors detected by satellites. Int. J. Appl.
Earth Obs. Geoinf. 11(6), 373-379 (2009). https://doi.org/10.1016/ j.jag.2009.07.003

13. Bhardwaj, A.; Singh, S.; Sam, L.; Joshi, P.K.; Bhardwaj, A.; Martín-Torres, F.J.; Kumar, R.: A review of remotely sensed land surface temperature anomaly as an earthquake precursor. Int. J. Appl. Earth Obs. Geoinf. 63, 158-166 (2017). https://doi.org/10. 1016/j.jag.2017.08.002

14. Mohamed, E. K.; Gahalaut, V. K.; Sekertekin, A.; Inyurt, S.: Atmospheric, ionospheric and earth-related variations associated with the 11th August 2012 earthquakes, Ahar Iran. J. Atmosp. SolarTerr. Phys. 216, 105595 (2021). https://doi.org/10.1016/j.jastp. 2021.105595

15. Ghamry, E.; Mohamed, E.K.; Abdalzaher, M.S.; Elwekeil, M.; Marchetti, D.; De Santis, A.; Hegy, M.; Yoshikawa, A.; Fathy, A.: Integrating pre-earthquake signatures from different precursor tools. J. IEEE. Access. 9, 33268-33283 (2021). https://doi.org/10. 1109/ACCESS.2021.3060348

16. Pulinets, S.A.; Ouzounov, D.; Ciraolo, L.; Singh, R.; Cervone, G.; Leyva, A.; Dunajecka, M.; Karelin, A.V.; Boyarchuk, K.A.; Kotsarenko, A.: Thermal, atmospheric and ionospheric anomalies around the time of the Colima M7.8 earthquake of 21 January 2003. Ann. Geophys. 24, 835-849 (2006). https://doi.org/10.5194/ angeo-24-835

17. Xie, T.; Kang, C.L.; Ma, W.Y.: Thermal infrared brightness temperature anomalies associated with the Yushu (China) Ms $=7.1$ earthquake on 14 April 2010. Nat. Hazards. Earth. Syst. Sci. 13(4), 1105-1111 (2013). https://doi.org/10.5194/nhess-13-1105-2013

18. Genzano, N.; Filizzola, C.; Paciello, R.; Pergola, N.; Tramutoli, V.: Robust Satellite Techniques (RST) for monitoring earthquakeprone areas by satellite TIR observations: The case of 1999 Chi-Chi earthquake (Taiwan). J. Asian Earth Sci. 114, 289-298 (2015). https://doi.org/10.1016/j.jseaes.2015.02.010

19. Tramutoli V, Coviello I, Eleftheriou A, Filizzola C, Genzano N, Lacava T, Lisi M, Makris JP, Paciello R, Pergola N, Satriano V (2015).: Long term (2004-2013) correlation analysis among SSTAs (Significant Sequences of TIR Anomalies) and Earthquakes (M>4) occurrence over Greece: examples of application within a multi-parametric system for continuous seismic hazard monitoring. In EGU General Assembly Conference Abstracts p 13582

20. Eleftheriou, A.; Filizzola, C.; Genzano, N.; Lacava, T.; Lisi, M.; Paciello, R.; Pergola, N.; Vallianatos, F.; Tramutoli, V.: Long-term RST analysis of anomalous TIR sequences in relation with earthquakes occurred in Greece in the period 2004-2013. Pure Appl Geophys 173(1), 285-303 (2016). https://doi.org/10.1007/s00024015-1116-8

21. Barkat, A.; Ali, A.; Rehman, K.; Awais, M.; Tariq, M.A.; Ahmed, J.; Iqbal, T.: Multi-precursory analysis of phalla earthquake (July 2015 Mw 51) near Islamabad Pakistan. Pure Appl. Geophys. 175(12), 4289-304 (2018). https://doi.org/10.1007/s00024-018-1927-5

22. Akhoondzadeh, M.; De Santis, A.; Marchetti, D.; Piscini, A.; Cianchini, G.: Multi precursors analysis associated with powerful Ecuador (MW = 78) earthquake of 16 April 2016 using Swarm satellites data in conjunction with other multi-platform satellite and ground data. Adv. Space Res. 61(1), 248-263 (2018). https://doi. org/10.1016/j.asr.2017.07.014

23. Mohamed, A.E.; El-Hadidy, M.; Deif, A.; Abou Elenean, K.: Seismic hazard studies in Egypt. NRIAG J Astro Geophys 1(2), 119-140 (2012). https://doi.org/10.1016/j.nrjag.2012.12.008

24. Cochran, J.R.: A model for development of the Red Sea. Bull Amer Assoc Petrol Geol 67, 41-69 (1983)

25. Cochran, J.R.; Gaulier, J.M.; LePichon, X.: Crustal structure and the mechanism of extension in the northern Red Sea: constraints from gravity anomalies. Tectonics 10, 1018-1037 (1991)

26. Martinez, F.; Cochran, J.R.: Structure and tectonics of the northern Red Sea: Catching a continental margin between rifting and drifting. Tectonophysics 150, 1-32 (1988) 
27. Neev, D.: The Pelusium line, a major transcontinental shear. Tectonophysics 38, T1-T8 (1977)

28. Ginzburg, A.; Gvirtzman, G.: Changes in the crust and upper mantle across the transition from Arabian Platform to the Mediterranean basin, evidences from seismic refraction and sedimentary studies in Israel and in Sinai. Sediment. Geol. 23(1-4), 19-36 (1979)

29. Orwig, E. R. (1982): Tectonic framework of northern Egypt and the eastern Mediterranean region. 6th Exploration Seminar. The Egyptian General Petroleum Corporation, Cairo

30. Neev, D.; Greenfield, L.; Hall, J.K.: Slice Tectonics in the Eastern Mediterranean Basin. In: Stanley, D.J.; Wezel, F.C. (Eds.) Geological Evolution of the Mediterranean Basin. Springer, New York (1985). https://doi.org/10.1007/978-1-4613-8572-1_12

31. Ben-Avraham, Z.: Structural framework of the Gulf of Elat (Aqaba), northern Red Sea. J Geophys Res: Solid Earth 90(B1), 703-726 (1985)

32. Harms, J.C.; Wray, J.L.: Nile Delta. In: Said, R. (Ed.) The geology of Egypt. Balkema, Rotterdam, Netherlands (1990)

33. Zeyen, H.; Volker, F.; Wehrle, V.; Fuchs, K.; Sobolev, S.V.; Altherr, R.: Styles of continental rifting: crust-mantle detachment and mantle plumes. Tectonophysics 278(1-4), 329-352 (1997)

34. Mosconi, A., Rebora, A., Venturino, G., Bocc, P. and Khalil M. H. (1996): Egypt -Nile Delta and North Sinai, Cenozoic tectonic model, a proposal. Egyptian General Petroleum Corporation, 13th Exploration Seminar 1: 203-223

35. Stanley, D.J.; Goodfriend, G.A.: Recent subsidence of the northern Suez Canal. Nature 388, 335-336 (1997)

36. Meshref, W.M.: Cretaceous tectonics and its impact on oil exploration in northern Egypt. Geol Soc Egypt, Special Publ 2, 199-244 (1999)

37. Girdler, R.W.; Evans, T.R.: Red Sea heat flow. Geophys. J. Int. 51(1), 245-251 (1977)

38. Morgan, P.; Swanberg, C.A.; Boulos, F.K.; Hennin, S.F.; El-Sayed, A.A.; Basta, N.Z.: Geothermal studies in northeast Africa. Annals Geol. Surv. Egypt 10, 971-987 (1980)

39. Morgan, P.; Boulos, F.K.; Swanberg, C.A.: Regional geothermal exploration in Egypt. Geophys. Prospect. 31, 361-376 (1983)

40. Morgan, P.; Boulos, F.K.; Hennin, S.F.; El-Sherif, A.A.; El-Sayed, A.A.; Basta, N.Z.; Melek, Y.S.: Heat flow in Eastern Egypt: the thermal signature of a continental breakup. J. Geody. 4, 107-131 (1985)

41. Boulos, F.K.: Some aspects of the geophysical regime of Egypt in relation to heat flow, groundwater and microearthquakes. In: Said, R. (Ed.) The Geology of Egypt, pp. 61-89. Rotterdam, A.A. Balkema (1990)

42. Feinstein, S.; Kohn, B.P.; Steckler, M.S.; Eyal, M.: Thermal history of the eastern margin of the Gulf of Suez, I. Reconstruction from borehole temperature and organic maturity measurements. Tectonophysics 266, 203-220 (1996)

43. Hosney, H.M.; Morgan, P.: Geothermal behavior and tectonic setting in the Northern Gulf of Suez Egypt. J. Environ. Sci. 19, 55-74 (2000)

44. Hoegh-Guldberg O, Cai R, Poloczanska E S, Brewer P. G, Sundby S, Hilmi K, Fabry V J, Jung S. (2014).: The ocean-supplementary material. In: Barros VR, Field CB, Dokken DJ, Mastrandrea MD, Mach KJ, Bilir TE, Chatterjee M, Ebi KL, Estrada YO, Genova RC, Girma B, Kissel ES, Levy AN, MacCracken S, Mastrandrea PR, White LL, (eds.), Climate Change: Impacts, Adaptation, and vulnerability. Part B: Regional aspects. Contribution of Working Group II to the Fifth Assessment Report of the Intergovernmental Panel on Climate Change. Cambridge: Cambridge University Press, p 1655-1731

45. Ghanea, M.; Moallem, P.; Momeni, M.: Building extraction from high-resolution satellite images in urban areas: recent methods and strategies against significant challenges Int. J. Remote Sens.
37, 5234-5248 (2016). https://doi.org/10.1080/01431161.2016. 1230287

46. El Kenawy, A.M.; Hereher, M.E.; Robaa, S.M.: An assessment of the accuracy of MODIS land surface temperature over Egypt using ground-based measurements. Remote. Sens. 11, 2369 (2019). https://doi.org/10.3390/rs11202369

47. Chakravarty, S.C.: Case Studies of SST variability derived from AQUA/AMSR-E satellite data near the sumatra region frequently affected by under-sea earthquakes. Open. Oceanograp. J. 3, 40-49 (2009)

48. Minnett, P.J.: The validation of sea surface temperature retrievals from spaceborne infrared radiometers. In: Barale, V.; Gower, J.F.R.; Alberotanza, L. (Eds.) Oceanography from Space, pp. 273-295. Springer, Berlin (2010)

49. Minnett, P.J.; Corlett, G.K.: A pathway to generating climate data records of sea-surface temperature from satellite measurements. Deep-Sea Res Part II Top. Stud. Oceanogr. 77-80, 44-51 (2012). https://doi.org/10.1016/j.dsr2.2012.04.003

50. Corlett G, Atkinson C, Rayner N, Good S, Fiedler E, McLaren A, Hoeyer J, Bulgin C. (2014): Product validation and intercomparison report, Project Document SST_CCIPVIR-UoL-001.http:// www.esa-sst-cci.org/PUG/documents. (accessed 20 August 2014).

51. Walton, C.C.; Pichel, W.G.; Sapper, J.F.; May, D.A.: The development and operational application of nonlinear algorithms for the measurement of sea surface temperatures with the NOAA polar-orbiting environmental satellites. J. Geophys. Res. 103, 27999-28012 (1998)

52. Martinez, F.; Cochran, J.R.: Geothermal measurements in the northern Red Sea: implications for lithospheric thermal structure and mode of the extension during continental rifting. J. Geophys. Res. 94, 12239-12266 (1989)

53. Ersoy, E.Y.; Çemen, İ; Helvac1, C.; Billor, Z.: Tectonostratigraphy of the Neogene basins in Western Turkey: implications for tectonic evolution of the Aegean extended region. Tectonophysics 635, 33-58 (2014)

54. Freund, F.: Seeking out Earth's warning signals. Nature 473(7348), 452 (2011). https://doi.org/10.1038/473452d

55. Varotsos, P.A.; Sarlis, N.V.; Skordas, E.S.: Scale-specific order parameter fluctuations of seismicity in natural time before mainshocks. Europhys. Lett. 96, 59002 (2011). https://doi.org/10.1209/ 0295-5075/96/59002

56. Yiğit, E.; Knížová, P.K.; Georgieva, K.; Ward, W.: A review of vertical coupling in the atmosphere-ionosphere system: effects of waves, sudden stratospheric warmings, space weather, and of solar activity. J. Atmosp. Solar-Terres. Phys. 141, 1-12 (2016). https:// doi.org/10.1016/j.jastp.2016.02.011

57. Hereher, M.; Bantan, R.; Gheith, A.; El-Kenawy, A.: Spatiotemporal variability of sea surface temperatures in the Red Sea and their implications on Saudi Arabia coral reefs. Geocarto. Int. (2021). https://doi.org/10.1080/10106049.2021.1922513

58. Zhao, C.; Lin, G.; Hobbs, B.E.; Mühlhaus, H.B.; Ord, A.; Wang, Y.: Finite element modelling of heat transfer through permeable cracks in hydrothermal systems with upward throughflow. Eng. Comput. 18(7), 996-1011 (2001). https://doi.org/10.1108/ 02644400110404000

59. Zhao, C.; Hobbs, B. E.; Ord, A.; Hornby, P.; Mühlhaus, H.; Peng, S.: Theoretical and numerical analyses of pore-fluid flow focused heat transfer around geological faults and large cracks. Comp Geotech 35(3), 357-371 (2008) 